\title{
Boreal summer intraseasonal oscillation in a superparameterized general circulation model: effects of air-sea coupling and ocean mean state
}

\author{
Yingxia Gao $^{1,2}$, Nicholas P. Klingaman ${ }^{2}$, Charlotte A. DeMott ${ }^{3}$, and Pang-Chi Hsu ${ }^{1}$ \\ ${ }^{1}$ Key Laboratory of Meteorological Disaster of Ministry of Education/Collaborative Innovation Center \\ on Forecast and Evaluation of Meteorological Disasters/NUIST-UoR International Research Institute, \\ Nanjing University of Information Science \& Technology, Nanjing, China \\ ${ }^{2}$ National Centre for Atmospheric Science-Climate and Department of Meteorology, \\ University of Reading, Reading, United Kingdom \\ ${ }^{3}$ Department of Atmospheric Science, Colorado State University, Fort Collins, Colorado, USA
}

Correspondence: Pang-Chi Hsu (pangchi@nuist.edu.cn)

Received: 28 February 2020 - Discussion started: 24 April 2020

Revised: 23 August 2020 - Accepted: 22 September 2020 - Published: 2 November 2020

\begin{abstract}
The effect of air-sea coupling on simulated boreal summer intraseasonal oscillation (BSISO) is examined using atmosphere-ocean-mixed-layer coupled (SPCAM3-KPP, referred to as SPK throughout) and uncoupled configurations of the superparameterized (SP) Community Atmospheric Model, version 3 (SPCAM3, referred to as SPA throughout). The coupled configuration is constrained to either observed ocean mean state or the mean state from the SP coupled configuration with a dynamic ocean (SPCCSM3), to understand the effect of mean-state biases on the BSISO. All configurations overestimate summer mean subtropical rainfall and its intraseasonal variance. All configurations simulate realistic BSISO northward propagation over the Indian Ocean and western Pacific, in common with other SP configurations.

Prescribing the $31 \mathrm{~d}$ smoothed sea surface temperature (SST) from the SPK simulation in SPA worsens the overestimated BSISO variance. In both coupled models, the phase relationship between intraseasonal rainfall and SST is well captured. This suggests that air-sea coupling improves the amplitude of simulated BSISO and contributes to the propagation of convection. Constraining SPK to the SPCCSM3 mean state also reduces the overestimated BSISO variability but weakens BSISO propagation. Using the SPCCSM3 mean state also introduces a 1-month delay to the BSISO seasonal cycle compared to SPK with the observed ocean mean state, which matches well with observa-
\end{abstract}

tion. Based on a Taylor diagram, both air-sea coupling and SPCCSM3 mean-state SST biases generally lead to higher simulated BSISO fidelity, largely due to their abilities to suppress the overestimated subtropical BSISO variance.

\section{Introduction}

The intraseasonal oscillation (ISO) is the most vigorous subseasonal signal in the tropics (Zhang, 2005). It interacts with other tropical climate and weather systems, such as the El Niño-Southern Oscillation (ENSO) and tropical cyclones (Kessler et al., 1995; Zhang and Gottschalck, 2002; McPhaden, 2004; Wu et al., 2007), and even the mid-latitude systems (Ding and Wang, 2007; Moon et al., 2013). Compared to the boreal winter ISO (i.e. the Madden and Julian Oscillation, or MJO; Madden and Julian, 1971, 1972), the boreal summer ISO (BSISO) shifts away from the Equator to the Asian summer monsoon (ASM) region (Wang et al., 2006; Lau and Waliser, 2012). Thus, the BSISO is connected strongly to the onset, active, and break phases of the ASM (Yasunari, 1979; Annamalai and Slingo, 2001; Lau and Waliser, 2012). The frequency of extreme events over the ASM region is also highly related to BSISO activity (Ren et al., 2013; Li et al., 2015; Hsu et al., 2016, 2017, 2020; Liu and Hsu, 2019). 
Realistic representation of the BSISO in climate models remains a challenge, although some improvements have been achieved in recent decades. The state-of-the-art general circulation models (GCMs) still have difficulty in simulating properly the BSISO spatial pattern (Sperber and Annamalai, 2008; Sperber et al., 2013; Hu et al., 2017) and its northwestsoutheast tilted rain band structure (Lin et al., 2006; Sabeerali et al., 2013). In contrast, its northward propagation, which is the most significant feature of the BSISO, is captured by most models. Fidelity for northward propagation improved in the models that contributed to the Coupled Model Intercomparison Project (CMIP) phase 5, relative to the CMIP phase 3 (Sabeerali et al., 2013; Sperber et al., 2013). Most models with reasonable northward propagation of the BSISO also simulate a good eastward propagation along the equatorial Indian Ocean.

The representation of convection is largely responsible for the ability of GCMs to simulate BSISO characteristics (Maloney and Hartmann, 2001; Randall et al., 2007; Jiang et al., 2016). Using the Hadley Centre atmospheric GCM (AGCM), Klingaman and Woolnough (2014) found that increasing the convective entrainment and detrainment rates considerably improved deficient MJO-like variability in the Indian and Pacific oceans. In recent years, studies have shown that "superparameterized" (SP) GCMs have high fidelity in simulating ISO variability (Benedict and Randall, 2009; Jiang et al., 2015; Neena et al., 2017). In SP GCMs, the traditional cumulus parameterization is replaced by a two-dimensional (2D) cloud-resolving model in each grid column to calculate the cloud and radiation physics tendencies (Khairoutdinov and Randall, 2003; Khairoutdinov et al., 2005). By comparing different versions of the National Center for Atmospheric Research (NCAR) Community Atmospheric Model (CAM), DeMott et al. (2014) showed that the SP CAM (SPA) gave better BSISO characteristics than the CAM with the standard convective parameterization.

Besides the convective parameterization scheme, the effect of air-sea interaction on simulated ISO variability has also received growing attention. By comparing the results of coupled GCMs (CGCMs) with the results of the AGCMs prescribed with observed SSTs, many studies found that the inclusion of air-sea coupling could produce a more realistic intraseasonal variability via improving the representation of the diurnal cycle at the air-sea interface (Waliser et al., 1999; Bernie et al., 2005; Danabasoglu et al., 2006; Misra et al., 2008; Stan, 2018). Besides the air-sea coupling process, the differences between simulated results may also come from ocean mean-state differences between AGCM and CGCM, as incorporating air-sea interaction in CGCMs inevitably introduces atmospheric and ocean mean-state biases. Due to the strong control on low-level moisture and convergence anomalies, such ocean mean-state biases may degrade simulated intraseasonal variability (Hendon, 2000; Inness et al., 2003; Sperber et al., 2005; Bollasina and Ming, 2013). Using the National Centers for Environmental Predic- tion (NCEP) coupled Climate Forecast System (CFS) model, Seo et al. (2007) showed that BSISO development and propagation were largely improved when the CGCM cold SST bias was removed via flux correction. They suggested that the role of air-sea interaction would be more accurate under an ocean mean state with smaller SST biases. To reduce the mean-state differences between CGCMs and AGCMs, timevarying SSTs from CGCMs should be used to drive AGCMs (Fu and Wang, 2004; Seo et al., 2007; Levine and Turner, 2012; DeMott et al., 2015). However, this quantifies the role of air-sea coupling only under the biased CGCM mean state.

Through flux correction, CGCMs can be constrained to a given climatological ocean state. Such constraint is more effective in CGCMs with simple ocean models, which lack ocean dynamics, as ocean dynamics may interfere with the prescribed flux correction. Simple ocean models also lack coupled modes of variability, such as the ENSO, feedbacks from which can influence the perceived effect of coupling on sub-seasonal variability (Klingaman and DeMott, 2020). The CGCMs with simplified model oceans are a useful tool to investigate the roles of air-sea coupling and mean-state biases in the simulation of BSISO. In this study, we examine the roles of air-sea interaction and mean-state biases in simulated BSISO using a configuration of SPA coupled to a mixed-layer ocean model, constrained to observed ocean mean state and simulated ocean mean state from the SP Community Climate System Model (CCSM), version 3 (SPCCSM3; Stan et al., 2010). The model experiments, validation data, and analysis methods are described in Sect. 2. In Sect. 3, we analyse the influence of air-sea coupling and mean-state biases on the spatial pattern and propagation of simulated BSISO. Results are discussed and summarized in Sects. 4 and 5, respectively.

\section{Model, experiments and methods}

\subsection{Models}

SPA (Khairoutdinov et al., 2005) is employed in this study, due to its high fidelity for simulated ISO (Jiang et al., 2015; Neena et al., 2017). It has a horizontal resolution of T42 and a vertical resolution of 30 levels. The embedded 2-D cloud- resolving model has 32 columns with a fine resolution ( $4 \mathrm{~km}$; Khairoutdinov and Randall, 2003). SPCCSM3 is the coupled configuration, in which SPA is coupled to the 3-D ocean model of the Parallel Ocean Program (POP; Danabasoglu et al., 2006), with active ocean dynamics. SPCCSM3 utilizes the low-resolution version $\left(\sim 3^{\circ}\right)$ of the POP, which has 40 vertical layers with the thickness of top layers being $10 \mathrm{~m}$ and exchanges SST and surface fluxes with SPA at $1 \mathrm{~d}$ coupling frequency. To understand the roles of air-sea interaction and SST mean-state biases in BSISO simulation, we couple SPA with the Multi-Column $K$ Profile Parameterization (MC-KPP) mixed-layer ocean model, referred to 
as SPK from now on. In the MC-KPP, there is only vertical mixing (Large et al., 1994), while ocean dynamics, such as horizonal or vertical advection or wind-driven upwelling, are absent. Besides, the air-sea coupled modes of variability (such as the ENSO) and potential feedbacks from these modes to intraseasonal variability are also absent. The MCKPP consists of many independent 1-D columns, with one column under each AGCM grid for coupling. Therefore, the horizontal resolution of MC-KPP is the same as that of SPA. The MC-KPP has a fine vertical resolution, with 100 points in a $1000 \mathrm{~m}$ water column, 70 of which are in the top $300 \mathrm{~m}$, and $\sim 1 \mathrm{~m}$ resolution in the top $20 \mathrm{~m}$. More details on SPK can be found in Klingaman and DeMott (2020).

Since MC-KPP lacks ocean dynamics, SPK must be constrained to a reference ocean climatology, which can be taken from an observation-based dataset, an ocean model simulation, or a CGCM simulation. To represent mean-ocean dynamics and correct for biases in surface fluxes, prescribed vertical profiles of heat and salt corrections are applied at each grid point at each time step. For each SPK simulation analysed here, a 10-year "relaxation" simulation is first performed, with a $15 \mathrm{~d}$ relaxation timescale toward the reference seasonal cycles of ocean temperature and salinity. The mean seasonal cycles of the temperature and salinity relaxation tendencies are then computed, smoothed with a $31 \mathrm{~d}$ running mean, and imposed as corrections in a "free-running" coupled integration with no relaxation, which displays only small SST biases against the reference climatology (Fig. 1). These free-running simulations are analysed here. More details on the correction method can be found in Hirons et al. (2015) and Klingaman and DeMott (2020).

\subsection{Experiments and validation data}

Two pairs of 50-year-long atmosphere-only (SPA) and coupled (SPK) models were analysed (Table 1). These simulations were also analysed for studying the MJO in Klingaman and DeMott (2020). Next, we explain the set-up of each experiment in detail.

To study the effect of mean-state biases on simulated BSISO, SPK is constrained to two ocean mean states: (1) the 1980-2009 climatology from the Met Office ocean analysis (Smith and Murphy, 2007) and (2) the climatology from the 20-year SPCCSM3 ("SPC" for short) simulation, which was analysed in Stan et al. (2010) and DeMott et al. (2014). The former is considered as the observed ocean state (Fig. 1c), against which SPC shows large cold SST biases throughout the Indo-Pacific in the boreal summer (Fig. 1f). These two coupled simulations are referred to as "SPK-OBS" and "SPK-SPC", respectively. Differences between the results of SPK-OBS and those of SPK-SPC can reveal the effect of SPC mean-state SST biases on the simulated BSISO. To investigate the effect of air-sea interaction on simulated BSISO under the observed ocean mean state, the time-varying SSTs from SPK-OBS are prescribed in an SPA simulation ("SPA-
KOBS"). The $31 \mathrm{~d}$ smoothed SST is used to remove the highfrequency variability of SST and avoid erroneous positive feedbacks between SSTs, surface fluxes, and precipitation (see DeMott et al. (2015) and references therein). Similarly, we prescribe the $31 \mathrm{~d}$ smoothed SST from SPK-SPC to SPA to understand the air-sea coupling effect under the SPC mean state ("SPA-KSPC") through the comparison with SPK-SPC. Table 1 summarizes all four experiments.

The validation data used in this study include (1) daily outgoing longwave radiation (OLR) from the National Oceanic and Atmospheric Administration (NOAA) at a resolution of $2.5^{\circ} \times 2.5^{\circ}$ for 1986-2016 (Liebmann and Smith, 1996), (2) daily precipitation from the Global Precipitation Climatology Project (GPCP; Huffman et al., 2001) at a resolution of $1^{\circ} \times 1^{\circ}$ for 1997-2016, and (3) daily variables from the European Centre for Medium-range Weather Forecasts (ECMWF) Interim (ERAI) reanalysis dataset at a resolution of $1.5^{\circ} \times 1.5^{\circ}$ (Dee et al., 2011). The variables from the ERAI include $850 \mathrm{hPa}$ wind, SST, surface variables related to latent heat and sensible heat ( $\mathrm{LH}$ and $\mathrm{SH}$ ) fluxes, and 3$\mathrm{D}$ variables associated with moist static energy (MSE; Maloney, 2009). Note that ERAI SST was the boundary condition prescribed for the ERAI. We analyse the period of 19862016 of ERAI data for compatibility with Gao et al. (2019).

\subsection{Methods}

The BSISO convective intensity is represented by $20-100 \mathrm{~d}$ filtered variability of boreal summer (May-October) precipitation, OLR, or MSE, depending on the process-oriented diagnostic applied. To reveal the overall propagation features of BSISO convection, lead-lag regression analysis is performed on area-averaged, filtered precipitation or OLR. Here, we use precipitation. Since the Indian and Pacific basins exhibit different basic states (Lau and Waliser, 2012), we compute propagation over one region in each basin: the eastern Indian Ocean $\left(0-10^{\circ} \mathrm{N}, 80-90^{\circ} \mathrm{E}\right)$ and western $\mathrm{Pa}$ cific $\left(0-10^{\circ} \mathrm{N}, 130-140^{\circ} \mathrm{E}\right)$.

DeMott et al. (2016) and Gao et al. (2019) provided a useful diagnostic method to quantitatively assess the contribution of intraseasonal SST variability to the MSE budget of ISO in the boreal winter and boreal summer, respectively. The temporal and spatial evolution of column-integrated MSE $(\langle m\rangle)$ is highly consistent with that of anomalous precipitation; and positive values of the time change of $\langle m\rangle$ $(\partial\langle m\rangle / \partial t)$ leads $90^{\circ}$ ahead of the convection. Thus, the physical processes that modulate $\langle m\rangle$ and $\partial\langle m\rangle / \partial t$ can be considered as the mechanisms responsible for the maintenance and propagation of convections, respectively. We employ the same approach to understand oceanic feedbacks to the simulated BSISO and compare these feedbacks to those in reanalysis data. Intraseasonal SST can affect atmospheric convection through modifying $\mathrm{LH}$ and $\mathrm{SH}$ fluxes and hence MSE, via the near-surface gradients in specific humidity and temperature. Based on decomposition of surface bulk formulae 

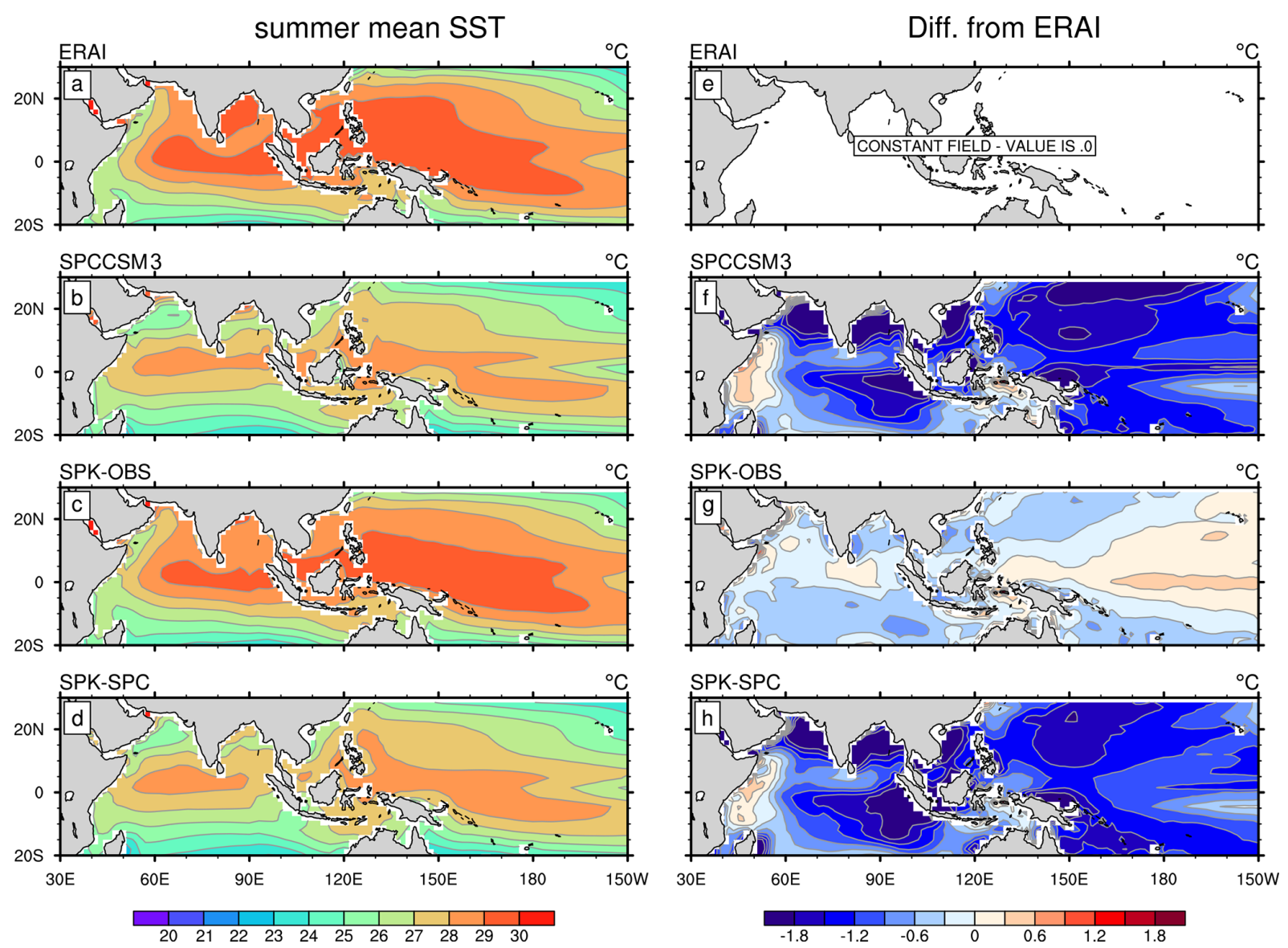

Figure 1. May-October mean SST for (a) ERAI, (b) SPCCSM3, (c) SPK-OBS, and (d) SPK-SPC. Panels (f-h) are calculated differences between (b-d) and (a).

Table 1. List of simulations analysed in this study, including the experiment name, model, ocean climatology condition used by the model to constrain (coupled model) or as forcing (atmospheric-only model), and design purpose.

\begin{tabular}{llll}
\hline Exp & Model & Ocean surface & Purpose \\
\hline SPK-OBS & SPK & $\begin{array}{l}\text { SST climatology from observation } \\
\text { SPT }\end{array}$ & $\begin{array}{l}\text { Understanding ocean mean-state bias effect } \\
\text { (SPK-OBS vs. SPK-SPC) }\end{array}$ \\
\hline SPA-KOBS & SPA & 31 d smoothed SST from SPK-OBS & $\begin{array}{l}\text { Understanding air-sea coupling effect under } \\
\text { observed mean state (vs. SPK-OBS) }\end{array}$ \\
\hline SPA-KSPC & SPA & 31 d smoothed SST from SPK-SPC & $\begin{array}{l}\text { Understanding air-sea coupling effect under } \\
\text { SPC mean state (vs. SPK-SPC) }\end{array}$ \\
\hline
\end{tabular}

(Weare et al., 1981), SST modulation of surface fluxes is represented as the difference between fluxes calculated using the full and $61 \mathrm{~d}$ smoothed SST. These SST-modulated fluxes are then projected onto $\langle m\rangle$ and $\partial\langle m\rangle / \partial t$ to reveal the oceanic feedbacks to the maintenance and propagation of BSISO convection, respectively. More details can be found in DeMott et al. (2016) and Gao et al. (2019).

We employ the BSISO indices of Lee et al. (2013) to investigate the simulated convective features in each BSISO phase. First, daily anomalies are computed as the departure from the climatological annual cycle and a $120 \mathrm{~d}$ running mean. A multi-variate empirical orthogonal function (MVEOF) is then performed on the combination of OLR and $850 \mathrm{hPa}$ zonal wind $\left(u_{850}\right)$ anomalies, each normalized by their respective area-mean standard deviation over the ASM region $\left(10^{\circ} \mathrm{S}-40^{\circ} \mathrm{N}, 40-160^{\circ} \mathrm{E}\right)$ during the boreal summer. The first two leading principal components (PC1 and PC2) define the BSISO indices, which separate the BSISO life cycle into eight phases. For model results, normalized OLR and $u_{850}$ anomalies are projected onto the observed EOF 
summer mean PRECT and 850-hPa wind
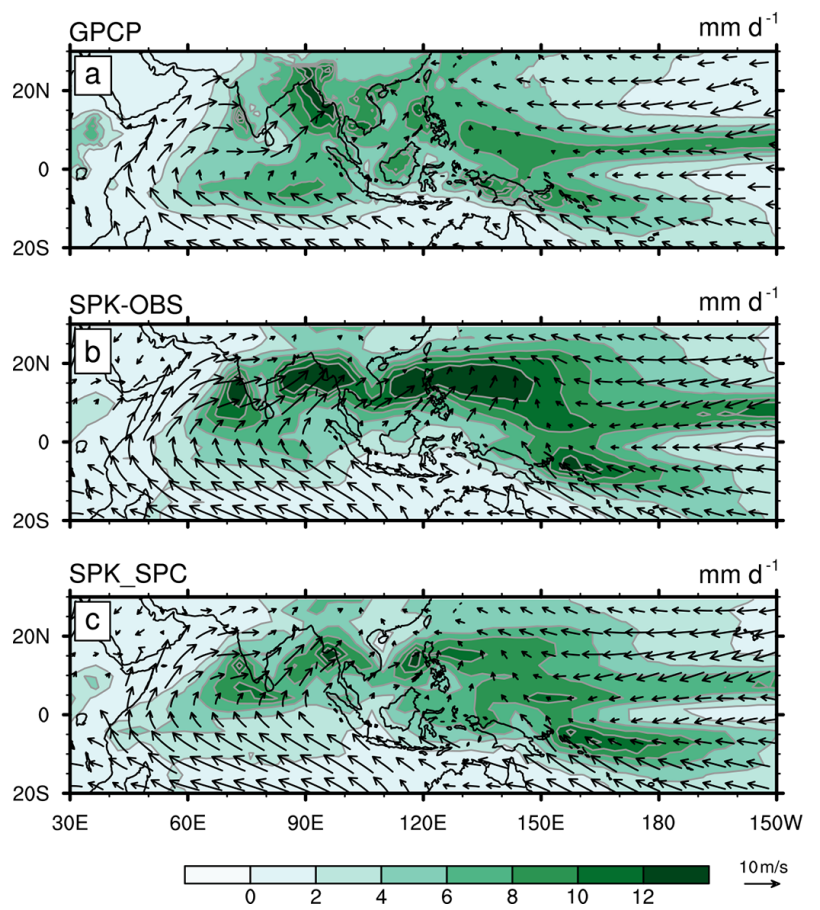
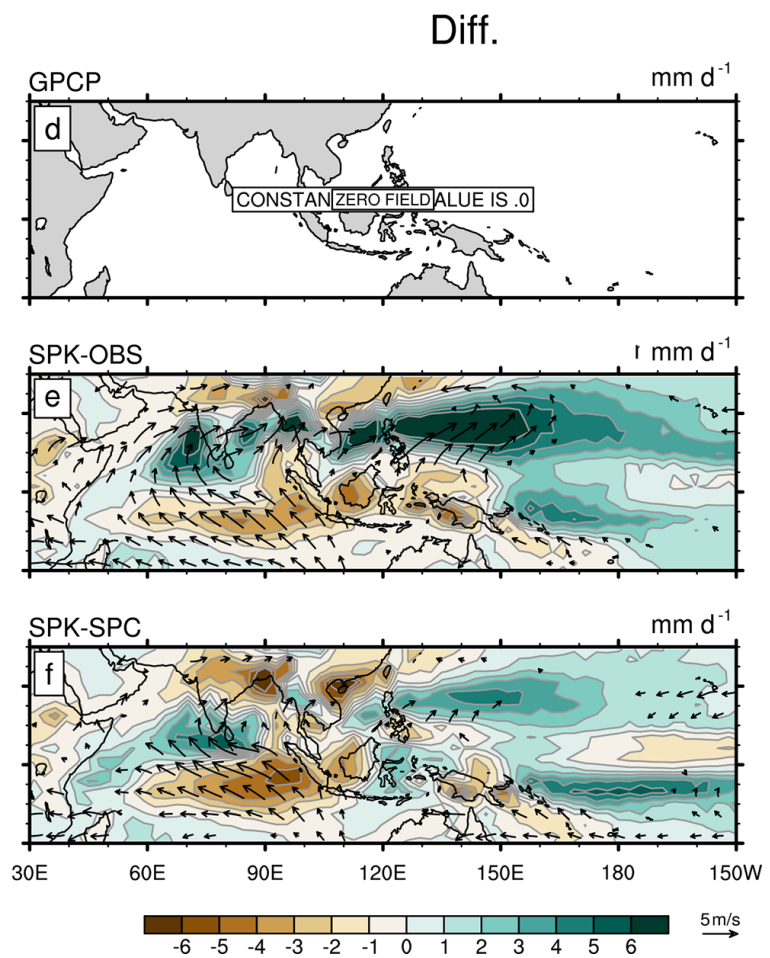

Figure 2. May-October mean precipitation (shading) and $850 \mathrm{hPa}$ wind (vector; with amplitude $>3.5 \mathrm{~m} \mathrm{~s}^{-1}$ ) for (a) GPCP precipitation and ERAI $850 \mathrm{hPa}$ wind, (b) SPK-OBS, and (c) SPK-SPC. Panels (e, f) are calculated differences between (b, c) and (a).

modes to obtain the model PCs. This approach helps to fairly assess how well the model experiments simulate the observed BSISO because the projected results (model PCs) can be directly compared to observations (Sperber et al., 2008, 2013; DeMott et al., 2019). Model-simulated BSISO phase composites are constructed based on these PCs. Consistent with Lee et al. (2013), only strong BSISO events $\left(\sqrt{\mathrm{PC}^{2}+\mathrm{PC}^{2}}>1.5\right)$ are selected for phase composites.

\section{Results}

\subsection{Mean state and intraseasonal variability}

Previous studies indicated that ISO variability is closely related to the climatological state of convection (Wheeler and Kiladis, 1999; Sperber et al., 2000; Waliser et al., 2003). Thus, we first examine the summer mean precipitation and $850 \mathrm{hPa}$ wind (Fig. 2). In GPCP, substantial rainfall appears over the ASM region (Fig. 2a). In common with the SPA simulation (DeMott et al., 2011), SPK-OBS overestimates subtropical rainfall $\left(10-20^{\circ} \mathrm{N}\right)$, particularly in the western North Pacific (Fig. 2b and e), but underestimates rainfall over the southern Indian Ocean, Maritime Continent and India north of $20^{\circ} \mathrm{N}$. These precipitation biases are associated with low-level wind biases. Simulated mean westerlies extend into the western North Pacific, increasing convergence across the band of subtropical enhanced precipitation. In
SPK-SPC (Fig. 2c), which is constrained to the cold climatological SPC SST (Fig. 1d), rainfall is reduced compared to that in SPK-OBS: wet biases are reduced while dry biases become more severe over the Indian Ocean and western North Pacific (Fig. 2e and f). The SPC mean-state SST bias tends to suppress the mean precipitation. Mean precipitation fields in SPA-KOBS and that in SPK-OBS (SPA-KSPC and SPK-SPC) are nearly the same (not shown).

Figure 3 illustrates the standard deviations of intraseasonal SST and precipitation variability. SST variability is underestimated over the Indian Ocean and equatorial Pacific in all simulations. In the off-equatorial Pacific, we see more intraseasonal SST variability in SPK-OBS but less SST variability in SPK-SPC (Fig. 3b and c), which may be related to the less SST variability in SPC as a consequence of a coarse horizontal resolution of POP. Prescribing the $31 \mathrm{~d}$ smoothed SST from SPK-OBS (SPK-SPC) to SPAKOBS (SPA-KSPC) strongly reduces intraseasonal SST, as expected (Fig. 3d and e). The right-column panels in Fig. 3 show the intraseasonal rainfall from each dataset (Fig. $3 \mathrm{f}-$ j). Compared to GPCP (Fig. 3f), all simulations significantly overestimate subtropical intraseasonal precipitation variability $\left(10-20^{\circ} \mathrm{N}\right)$, where mean rainfall is also overestimated (Fig. 2). This reinforces that model BSISO biases are largely associated with incorrect representation of mean rainfall (Sperber and Annamalai, 2008; Sabeerali et al., 2013; Hu et al., 2017). The overestimate of intraseasonal rainfall in SPK- 

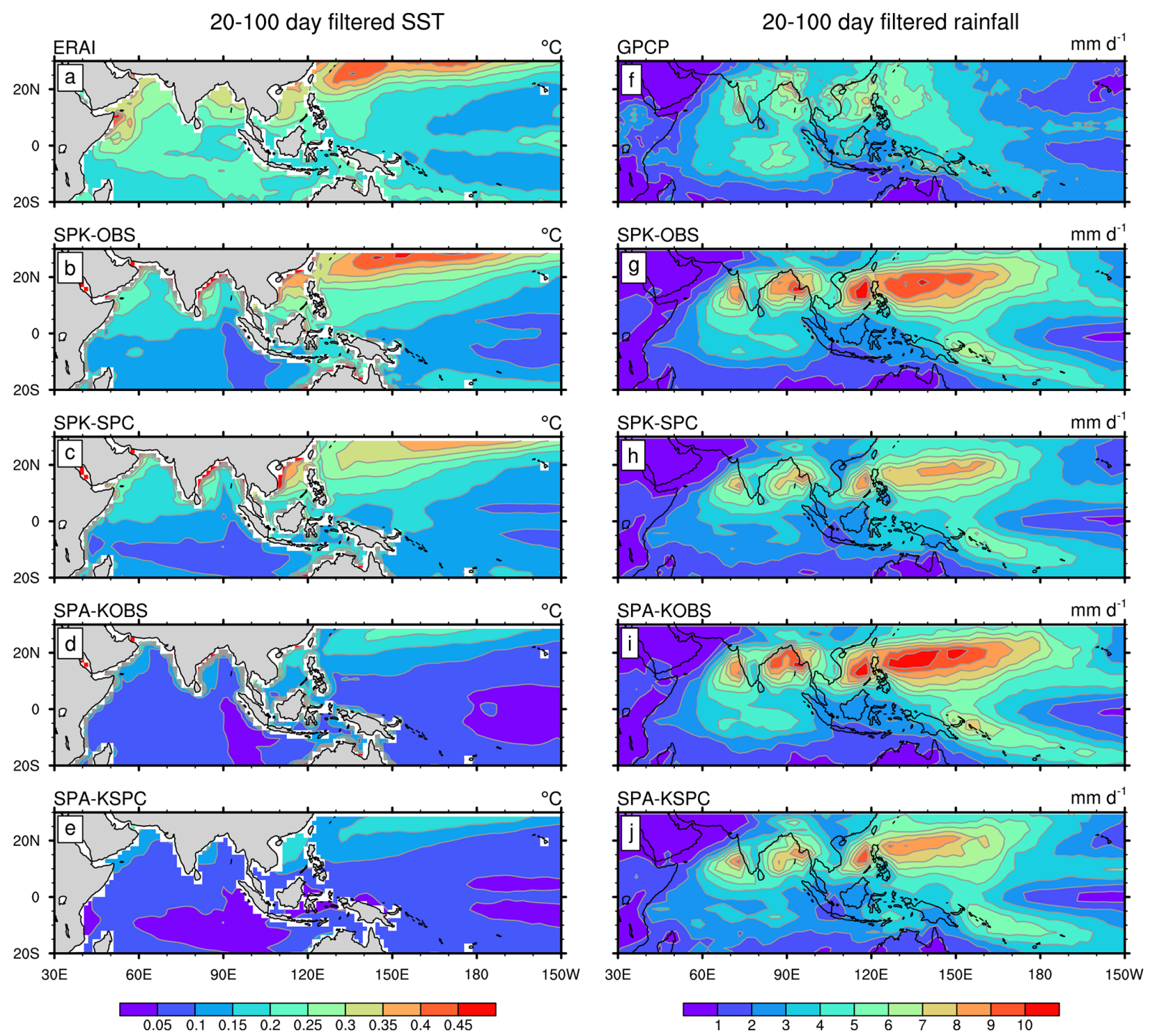

Figure 3. May-October standard deviations of 20-100 d filtered (a-e) SST and (f-j) precipitation for (a, f) ERAI SST and GPCP precipitation, (b, g) SPK-OBS, (c, h) SPK-SPC, (d, i) SPA-KOBS, and (e, j) SPA-KSPC.

SPC (Fig. 3h) is smaller than that in SPK-OBS (Fig. 3g), consistent with the lower mean rainfall in SPK-SPC. SPAKOBS (Fig. 3i) and SPA-KSPC (Fig. 3j) show increases in intraseasonal rainfall relative to SPK-OBS and SPK-SPC, respectively. This indicates that both cold SST biases and airsea coupling exert negative feedbacks on BSISO convection and improve the simulated BSISO amplitude.

\subsection{Northward propagation of BSISO}

Lag regression analysis is employed to understand the simulated BSISO propagation in each experiment. Over the Indian Ocean, area-averaged intraseasonal precipitation and SST (over $80-90^{\circ} \mathrm{E}$ ) are regressed onto area-averaged intraseasonal precipitation (over $0-10^{\circ} \mathrm{N}, 80-90^{\circ} \mathrm{E}$ ) time series (Fig. 4). In observation, the convective anomaly orig- inates south of the Equator and propagates southward to $10-15^{\circ} \mathrm{S}$ and northward into the Bay of Bengal (Fig. 4a). All simulations capture the northward propagation, confirming the high fidelity of SPA in simulating BSISO northward propagation (DeMott et al., 2014; Neena et al., 2017). However, the simulations fail to capture the southward propagation branch. Other significant biases can be seen in the locations of maximum convections of BSISO. The simulated convective centre shifts northward $\left(10^{\circ} \mathrm{N}\right)$ relative to observation $\left(5^{\circ} \mathrm{N}\right)$. A weaker propagating signal is observed under the SPC mean state than under the observed mean state for both SPK and SPA, especially over the subtropical regions from Lag 0 to Lag 20 (Fig. 4b-e). This is consistent with weaker BSISO variability under the SPC mean state (Fig. $3 \mathrm{~g}-\mathrm{j}$ ), suggesting that cold tropical mean SST biases are unfavourable for BSISO variability and northward propaga- 
IO (80E-90E, 0-10N)
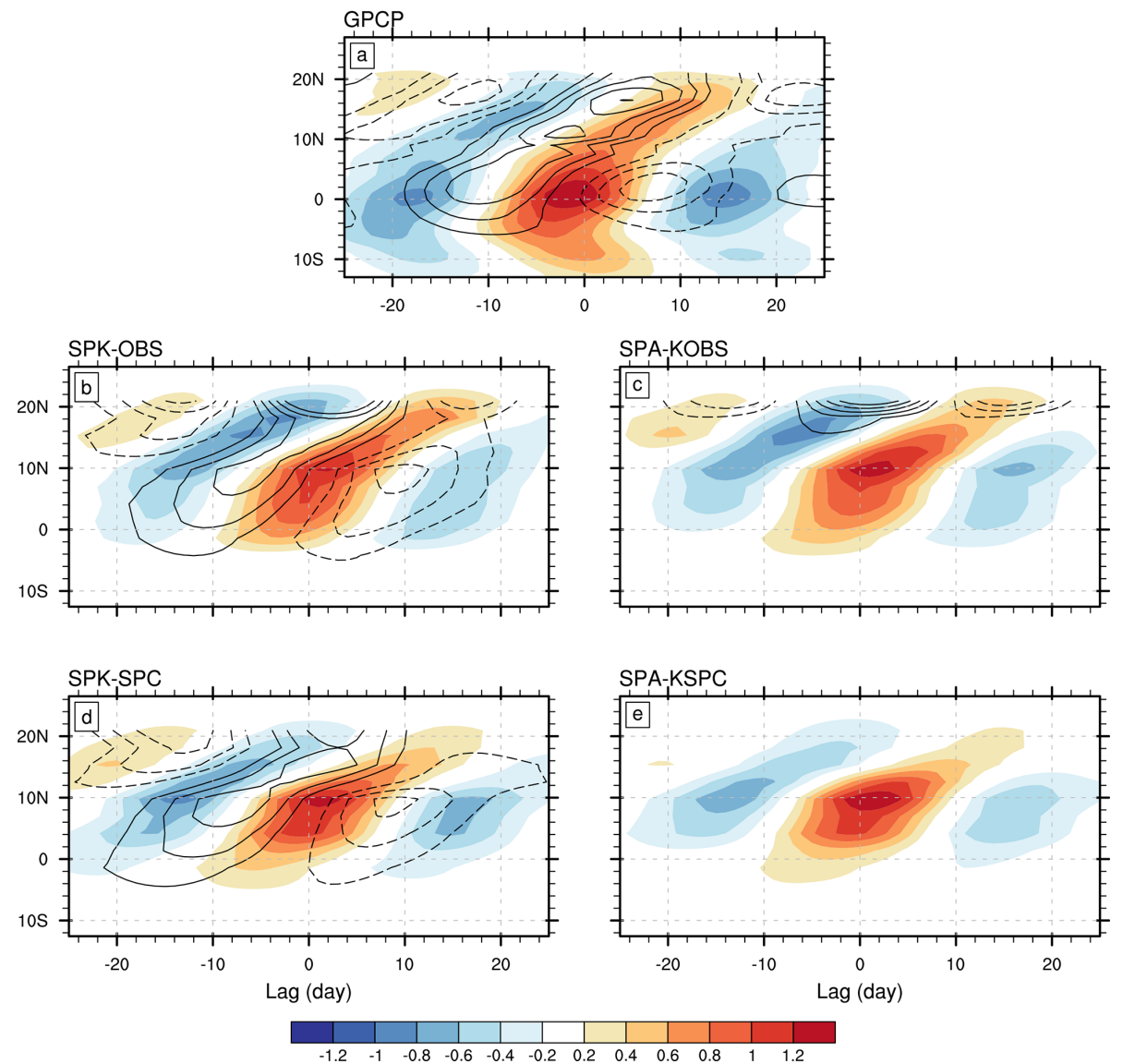

Figure 4. Lagged regression coefficients of $80-90^{\circ}$ E averaged intraseasonal precipitation (shading; $\left.\mathrm{mm} \mathrm{d}^{-1}\left(\mathrm{~mm} \mathrm{~d}^{-1}\right)^{-1}\right)$ and SST (contour; $\left.{ }^{\circ} \mathrm{C}\left(\mathrm{mm} \mathrm{d}^{-1}\right)^{-1}\right)$ onto $\left(0-10^{\circ} \mathrm{N}, 80-90^{\circ} \mathrm{E}\right)$ averaged intraseasonal precipitation for (a) GPCP precipitation and ERAI SST, (b) SPK-OBS, (c) SPA-KOBS, (d) SPK-SPC, and (e) SPA-KSPC. Contour interval is $0.001^{\circ} \mathrm{C}\left(\mathrm{mm} \mathrm{d}^{-1}\right)^{-1}$, and zero contour is omitted.

tion. In SPA, the amplitude of convective maxima increases relative to that in SPK, but with weaker propagation (Fig. 4be). Air-sea coupling plays a similar role in BSISO convection under both observed and cold mean states: it damps BSISO amplitude but supports northward propagation over the eastern Indian Ocean.

The BSISO northward propagation over the western Pacific is shown in Fig. 5. The observed convection also originates south of the Equator but propagates only north, into the western North Pacific (Fig. 5a). These characteristics are properly simulated by all experiments (Fig. $5 \mathrm{~b}-\mathrm{e}$ ). As in the Indian Ocean, due to the large overestimate of subtropical BSISO variability, the strongest simulated convection moves north compared to observation. It is notable that considerable suppressed off-equatorial convection leads the strongest convection by $\sim 1$ week, which degrades model performance. Over the western Pacific, mean-state biases also reduce the northward propagating signal in SPK-SPC (SPA-KSPC) relative to that in SPK-OBS (SPA-KOBS). Air-sea interaction seems to play only a small role in the BSISO northward prop- agation over the western Pacific, as there is no substantial difference between SPK and SPA under either ocean mean state (Fig. 5b-e).

\subsection{Quantitative contribution of SST fluctuation to BSISO}

The temporal and spatial evolutions of BSISO and SST variability over the Indian Ocean and western Pacific are shown in Figs. 6 and 7, respectively. Over the Indian Ocean, the warm SSTs in observation always lead enhanced convection, with maxima north-northeast of the convective centre (Fig. 6a, f, and k). The SST-rainfall phase relationship is properly represented in SPK but misrepresented in SPA. However, SPK shows a shorter delay between off-equatorial suppressed convection and warm SST relative to observation, which can be more clearly revealed in Fig. 4. This suggests the ocean responds more quickly to BSISO convection in SPK than in observation, which might be caused by the lack of ocean dynamics in MC-KPP. Alternatively, the high coupling frequency $(15 \mathrm{~min})$ and fine ocean vertical resolution 
WP $(130 \mathrm{E}-140 \mathrm{E}, 0-10 \mathrm{~N})$
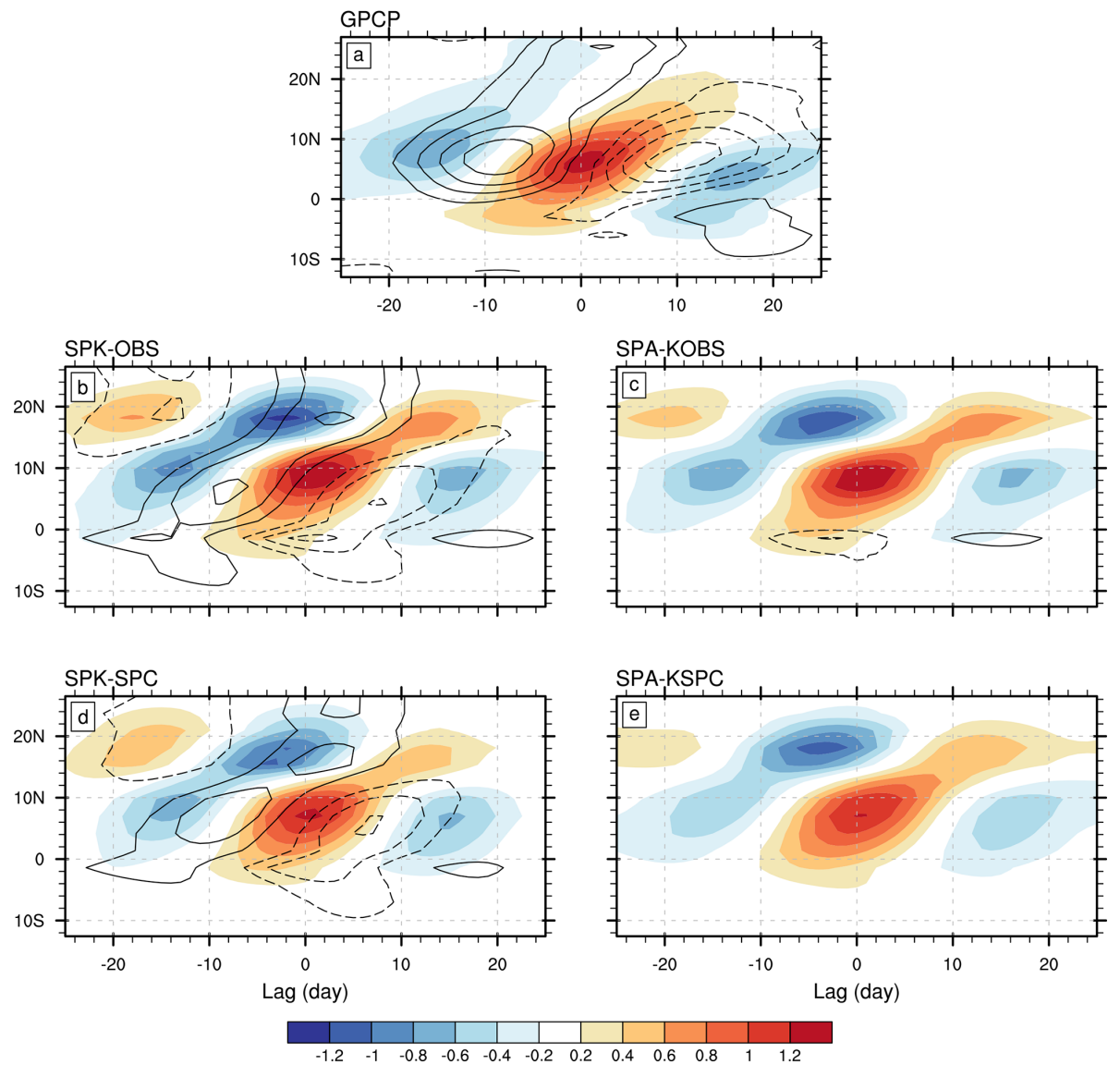

Figure 5. Same as Fig. 4, except for $130-140^{\circ}$ E averaged intraseasonal precipitation and SST regressed onto $\left(0-10^{\circ} \mathrm{N}, 130-140^{\circ} \mathrm{E}\right)$ averaged intraseasonal precipitation.

$(\sim 1 \mathrm{~m})$ in SPK may make the mixed-layer depth too sensitive to atmospheric convection. The SST anomalies in SPA are small due to the $31 \mathrm{~d}$ smoothing applied (Fig. 6d, e, i, j, n, and o). The size of the convective regions in all model simulations is smaller than that in observations, which may imply a deficient BSISO propagation. Compared to SPK-OBS, the convective region reduces when either the SPC mean state is used (SPK-SPC) or air-sea coupling is removed (SPAKOBS and SPA-KSPC). To some degree, it reflects the negative (positive) role of mean-state biases (air-sea interaction) in supporting the propagating BSISO signal, in agreement with Fig. 4.

Over the western Pacific, SPK reproduces the observed phase relationship between the convection and SST anomalies: a near-quadrature relationship over the equatorial regions (Fig. 7a-c), but a shift of warm SST anomalies toward the suppressed convective regions in the off-equatorial regions (Fig. $7 \mathrm{f}-\mathrm{h}$ and $\mathrm{k}-\mathrm{m}$ ). This phase relationship can also be clearly revealed in the Hovmöller diagram (Fig. 5). However, SPK produces substantial suppressed convection north of the active convection over the western North Pacific, con- sistent with Fig. 5. Besides, a simulated warm SST appears north of the convective centre, while the ERAI SST maximum is always located northwest of the convective centre. This implies that the simulated SST may be favourable for the northward but unfavourable for the westward propagation of the simulated BSISO convection over the western Pacific. Imposing the SPC mean state weakens the simulated convection. In SPA, the intraseasonal SST is very small by design.

As revealed by Gao et al. (2019), intraseasonal SST can affect the BSISO by modulating surface LH and SH fluxes. The temporal and spatial distributions of SST-modulated fluxes are highly coherent with those of SST anomalies themselves. Therefore, the evolutions of SST anomalies shown in Figs. 6 and 7 can also roughly reveal the evolutions of SSTmodulated surface fluxes. By regressing the SST-modulated flux anomalies onto the BSISO $\langle m\rangle$ and $\partial\langle m\rangle / \partial t$, Fig. 8 illustrates the "SST effect" on the maintenance and propagation of convection. In the ERAI, intraseasonal SST supports $\langle m\rangle$ in the central Indian Ocean and Bay of Bengal but destroys $\langle m\rangle$ in the western North Pacific (Fig. 8a). The inter-basin differences are linked to the differences in the 
$1 \mathrm{O}(80 \mathrm{E}-90 \mathrm{E}, 0-10 \mathrm{~N})$
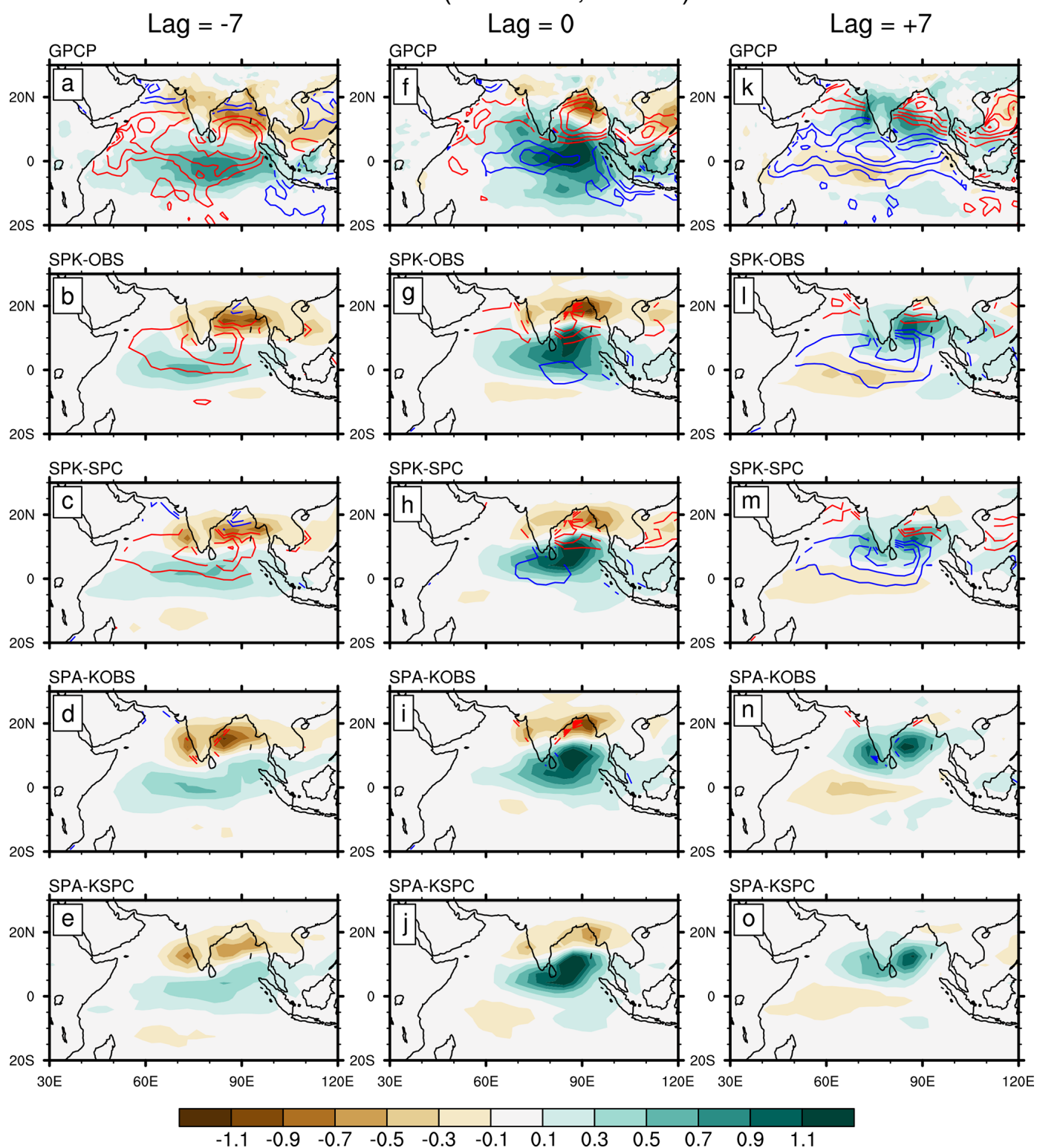

$\begin{array}{llllllllllll}-1.1 & -0.9 & -0.7 & -0.5 & -0.3 & -0.1 & 0.1 & 0.3 & 0.5 & 0.7 & 0.9 & 1.1\end{array}$

Figure 6. Regression coefficients of intraseasonal precipitation (shading; $\left.\mathrm{mm} \mathrm{d}^{-1}\left(\mathrm{~mm} \mathrm{~d}^{-1}\right)^{-1}\right)$ and SST (contour; $\left.{ }^{\circ} \mathrm{C}\left(\mathrm{mm} \mathrm{d}^{-1}\right)^{-1}\right)$ onto $\left(0-10^{\circ} \mathrm{N}, 80-90^{\circ} \mathrm{E}\right)$ averaged intraseasonal precipitation over the Indian Ocean at lags of (a-e) $-7,(\mathbf{f}-\mathbf{j})$ 0, and (k-o) $+7 \mathrm{~d}$, for $(\mathbf{a}, \mathbf{f}, \mathbf{k}) \mathrm{GPCP}$ precipitation and ERAI SST, (b, g, l) SPK-OBS, $(\mathbf{c}, \mathbf{h}, \mathbf{m})$ SPK-SPC, (d, i, n) SPA-KOBS, and (e, j, o) SPA-KSPC. The contour interval is $0.01{ }^{\circ} \mathrm{C}\left(\mathrm{mm} \mathrm{d}^{-1}\right)^{-1}$; positive (negative) values are represented by red (blue) lines.

SST-convection phase relationship (Gao et al., 2019). However, simulated SST anomalies in SPK largely damp the convection over the Bay of Bengal and western North Pacific (Fig. 8b and c), because of the quicker response of the SPK ocean to BSISO convection, combined with the erroneously strong suppressed convection just before the active phase. The negative SST effect on $\langle m\rangle$ agrees with the stronger subtropical BSISO variability in SPA than in SPK. For the BSISO propagation, the simulated SST anomalies play positive roles in $\partial\langle m\rangle / \partial t$ under both ocean mean states (Fig. 8g and h), but with a smaller contribution $(8 \%-12 \%)$ than that in the ERAI (12\%-20\%). A weak SST effect on the BSISO can still be found in SPA (Fig. 8d, e, i, and j), as these simulations retain some intraseasonal SST variability (Fig. 3). In summary, SST variability enhances the simulated amplitude of BSISO variability by suppressing the excessive subtropical convection and contributes to the propagation of convection over the entire BSISO region. 
WP (130E-140E, 0-10N)
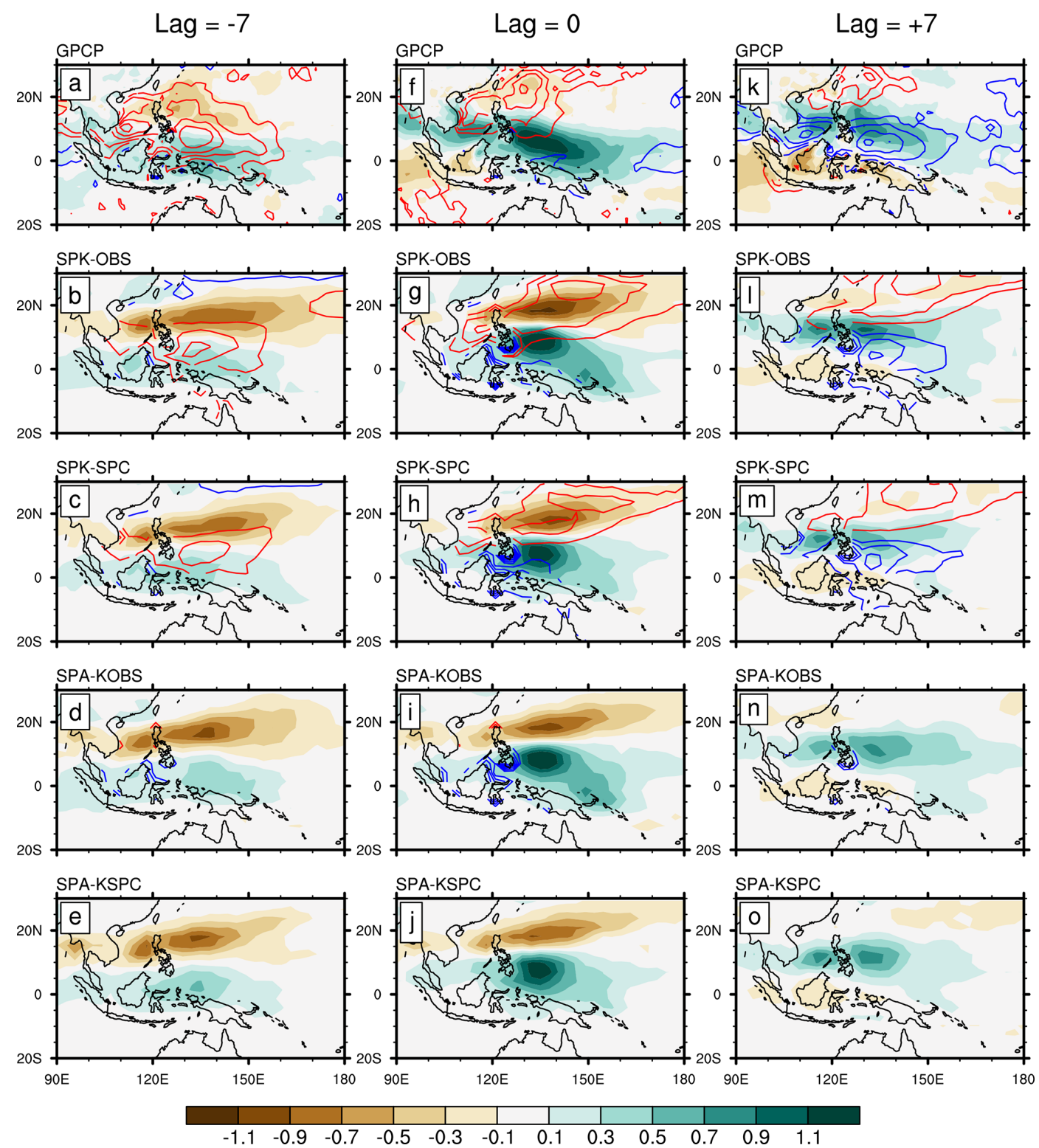

Figure 7. Same as Fig. 6, except for variables regressed onto $\left(0-10^{\circ} \mathrm{N}, 130-140^{\circ} \mathrm{E}\right)$ averaged intraseasonal precipitation over the western Pacific.

\subsection{BSISO indices}

Propagating BSISO characteristics can also be examined using the BSISO indices. Figure 9 shows the annual cycle of variance of each of the first four PCs from observation and model simulations. Since EOF analysis is only applied to May-October data, the PC time series for November-April are obtained by projecting OLR and $u_{850}$ anomalies onto the same EOF patterns.

In observation, $\mathrm{PC} 1$ has the largest variance throughout the boreal summer (Fig. 9a). It increases sharply from late April, maximizes in August, and is followed by PC2 with about a half-month delay. In contrast to PC1 and PC2, PC3 exhibits most of its variance in early summer (May-June). PC4 also has a broad peak, but its amplitude is much smaller than those of the other PCs. SPK-OBS produces a similar seasonal cycle of PC1 as observation, except for deficient variance in August-September, which largely reduces the amplitude difference between the first two PCs (Fig. 9b). Simulated PC1 in SPK-OBS also increases abruptly from late April, with a half-month delay between PC1 and PC2, which matches the observation well. However, PC1 in SPK-SPC begins to in- 


\section{SST effect}
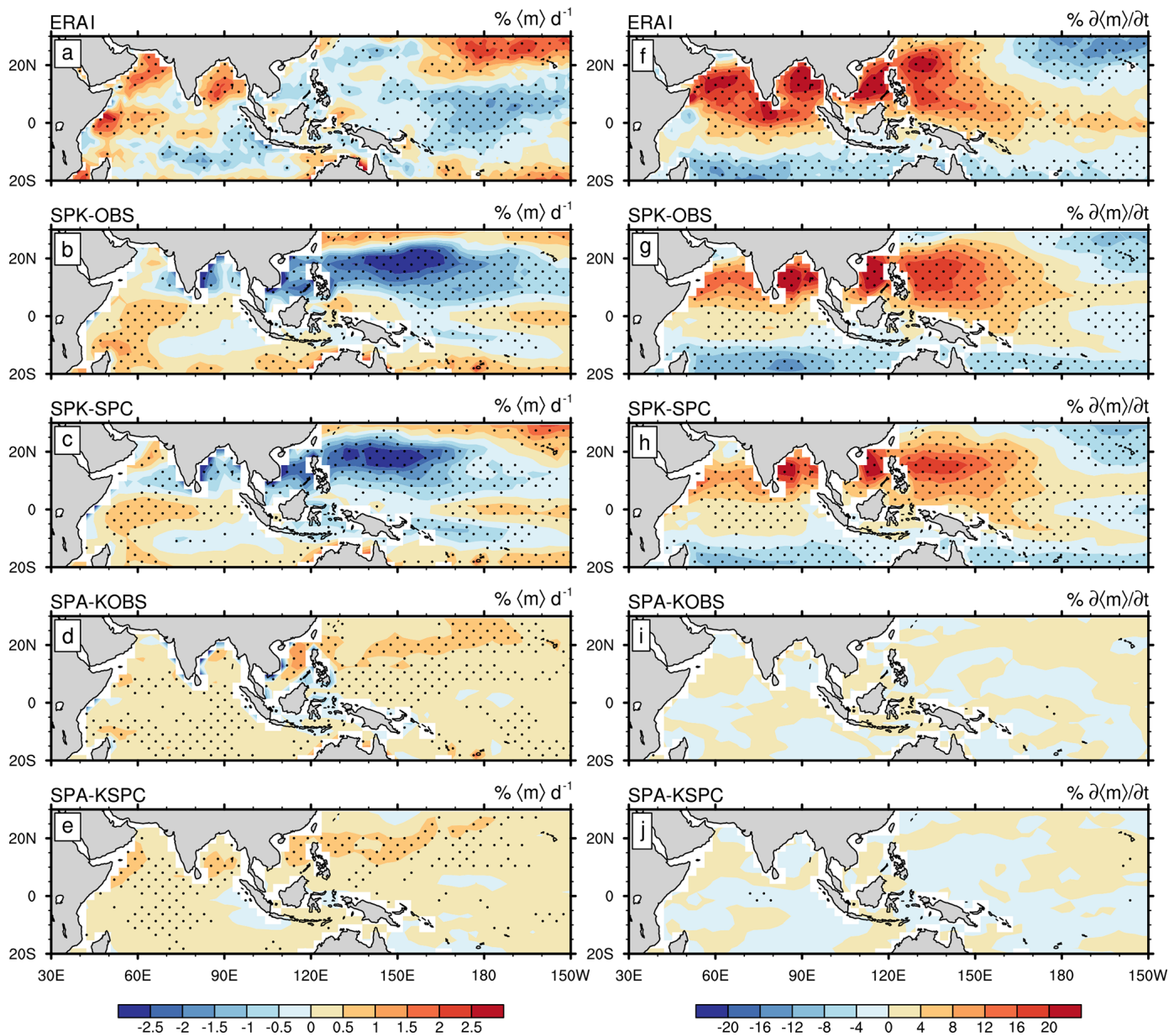

Figure 8. SST effect on (a-e) $\langle m\rangle$ and (f-j) $\partial\langle m\rangle / \partial t$ through the modification of surface turbulent fluxes for (a, f) ERAI, (b, g) SPK-OBS, $(\mathbf{c}, \mathbf{h})$ SPK-SPC, (d, i) SPA-KOBS, and (e, j) SPA-KSPC. Stippling indicates regression coefficient is significant at the $95 \%$ confidence level.

crease in late May (Fig. 9d), about 1 month later than the observation and SPK-OBS. The variance of the first two PCs in SPK-SPC has a much narrower peak and tails off from early July, without a second peak in October. This suggests that cold SST bias leads to a late onset of BSISO activity, and also strongly degrades the annual cycle of BSISO activity. In both SPK simulations, the amplitude of PC3 is smaller than that of PC4, indicating that the order of those simulated PCs is reversed. All model simulations show a similarly poor ability to simulate PC3 and PC4. Therefore, hereafter we only focus on PC1 and PC2. Removing air-sea coupling in SPA significantly increases the strength of $\mathrm{PC} 1$ relative to that in SPK (Fig. 9b-e). This suggests that the role of air-sea coupling in suppressing BSISO variability is mainly expressed through damping variability in PC1.

Based on the PC1 and PC2 time series, the BSISO life cycle is separated into eight phases, which represents the canonical northward-propagating BSISO (Annamalai and Sperber, 2005; Wang et al., 2005). Figure 10 shows the phase composites of anomalous precipitation and $850 \mathrm{hPa}$ wind from the observation and SPK-OBS. SPK-OBS displays a similar evolution of the structure of convection and circulation as the observation, but they have significant amplitude differences. The simulated precipitation variability is underestimated over the equatorial Indian Ocean, while a substantial overestimate appears over the off-equatorial regions. The simulated circulation matches well with the simulated convection: easterlies (westerlies) occur to the north (south) of the ascent; cyclonic (anticyclonic) circulations coincide with the active (suppressed) off-equatorial convection. However, the northwest-southeast tilted rainfall band in SPK-OBS is more zonal than that in GPCP (Fig. 10e and m), largely due to the poor representation of BSISO variability over the western Pacific. In observation, most strong BSISO events occur in phases 2, 5, 7, and 8. In contrast, in SPK-OBS, a stronger preference for simulated strong BSISO events appear in offequatorial regions (phases $3,4,7$, and 8) rather than in nearequatorial regions (phases 1, 2, 5, and 6). It implies that the 

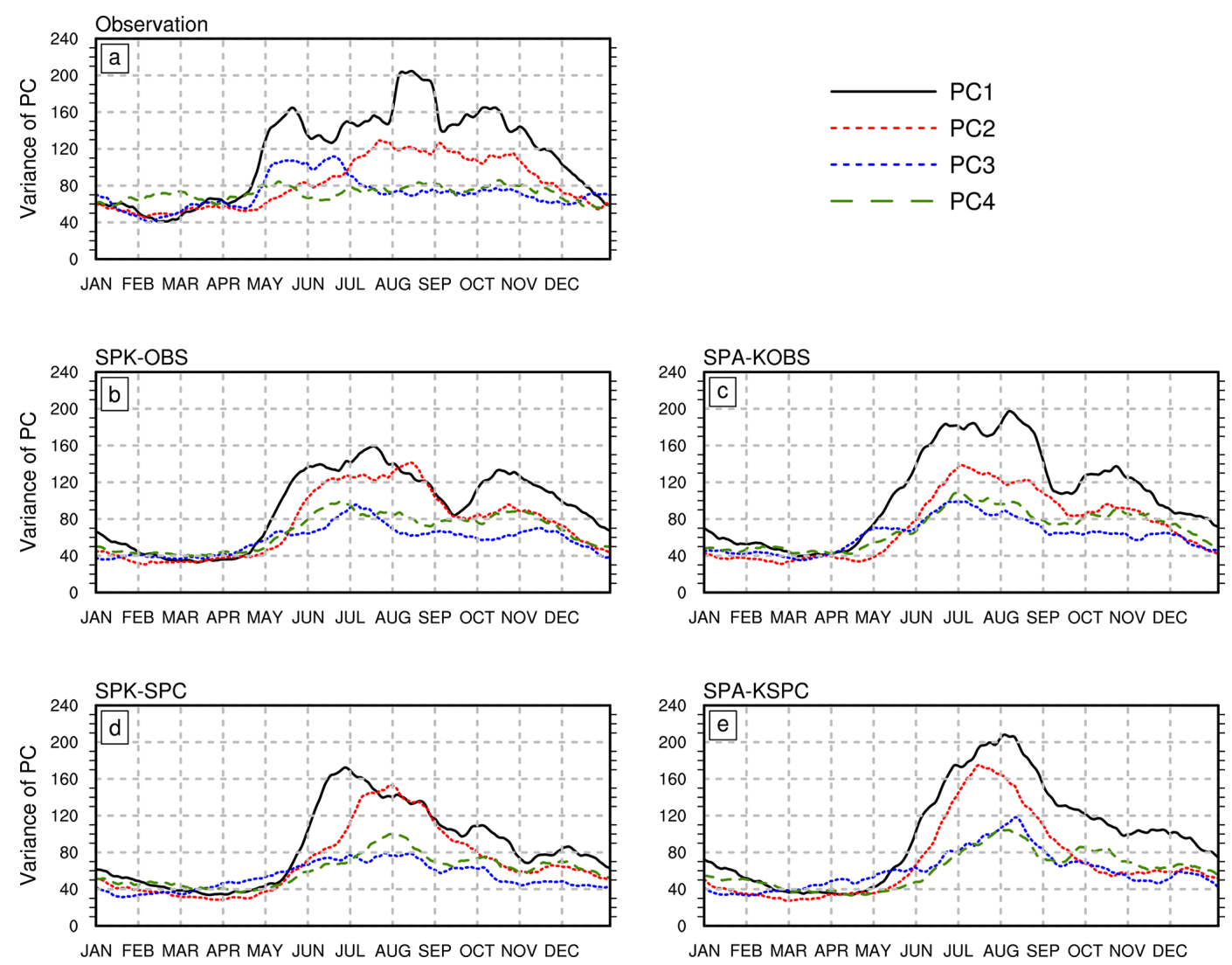

Figure 9. Seasonal cycle of variance of the four leading PCs for (a) NOAA OLR and ERAI $u_{850}$, (b) SPK-OBS, (c) SPA-KOBS, (d) SPKSPC, and (e) SPA-KSPC. A $30 \mathrm{~d}$ running mean is applied to the seasonal cycle of each variable.

BSISO variability is largely determined by the propagating BSISO signal (Sperber et al., 2013; Neena et al., 2017).

We further compute the frequency of strong BSISO events in each phase from each dataset (Fig. 11). Overall, there are fewer strong BSISO events in the simulations $(22.5 \%-$ $27.5 \%)$ than in observation $(\sim 33 \%)$, although the amplitude of simulated precipitation associated with these events is much larger. The frequency of stronger BSISO events becomes further reduced under the SPC ocean mean state than that under the observed ocean mean state. Consistent with Fig. 10, phases 2, 5, 7, and 8 show the highest frequencies in observation, while in SPK-OBS and SPK-SPC, most strong simulated BSISO events occur in phases $3,4,7$, and 8 . Removing air-sea coupling in SPA further increases the frequency of strong BSISO events in the off-equatorial regions, associated with the greater intraseasonal convective variability in SPA relative to that in SPK.

To quantitatively evaluate the performance of each simulation, we construct Taylor diagrams over the Indian Ocean $\left(10^{\circ} \mathrm{S}-20^{\circ} \mathrm{N}, 50-100^{\circ} \mathrm{E}\right)$ and western Pacific $\left(0-30^{\circ} \mathrm{N}\right.$, $110-160^{\circ} \mathrm{E}$ ), respectively (Fig. 12). These diagrams provide pattern correlation coefficients and root-mean-square errors of simulated intraseasonal precipitation against GPCP intraseasonal precipitation in each BSISO phase. Over the In- dian Ocean, the fidelity of each simulation varies from phase to phase (Fig. 12a). Generally, higher pattern correlations appear in equatorial phases (phases 1, 2, 5, and 6) than in offequatorial phases (phases 3, 4, 7, and 8). Under the observed ocean mean state, air-sea coupling improves the simulation fidelity in most phases, while the SPC ocean mean state and coupling under the SPC ocean mean state have little consistent effect on the simulated BSISO fidelity.

In almost all simulations, higher pattern correlations are found over the western Pacific (0.6-0.9) than over the Indian Ocean (0.5-0.8), but with much larger overestimates of amplitude (Fig. 12b). The overall simulation performance over the western Pacific is ranked as follows: SPK-SPC, SPA-KSPC, SPK-OBS, and SPA-KOBS. Simulations with the SPC ocean mean state perform better than those with the observed ocean mean state, in terms of both amplitude and distribution. Since the excessive subtropical rainfall variability is the biggest error in SPA, the underlying cold SSTs largely weaken the convection, which helps reduce the amplitude biases and improve the pattern correlation with observation. Air-sea coupling improves model performance under both ocean mean states, particularly in terms of suppressing the overestimated BSISO variability over the western North Pacific. 


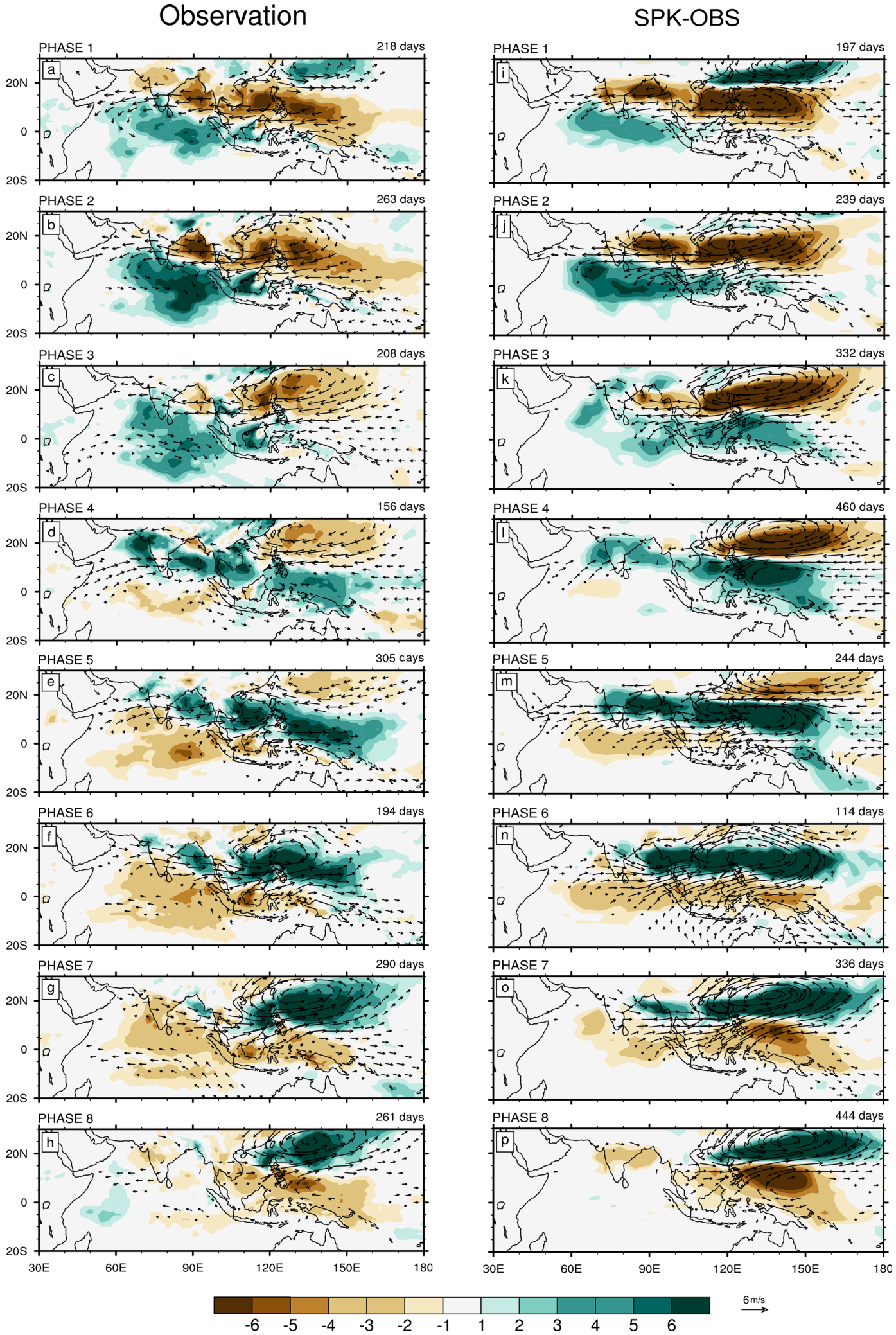

Figure 10. Composites of anomalous precipitation (shading; $\mathrm{mm} \mathrm{d}^{-1}$ ) and $850 \mathrm{hPa}$ wind (vector; with amplitude $>1 \mathrm{~m} \mathrm{~s}^{-1}$ ) in the BSISO life cycle from phase 1 to phase 8 for $(\mathbf{a}-\mathbf{h})$ GPCP precipitation and ERAI $850 \mathrm{hPa}$ wind and (i-p) SPK-OBS. The number of days for the phase composite is shown at the right corner above each panel. Only strong BSISO events (amplitude $\geq 1.5$ ) are selected. 


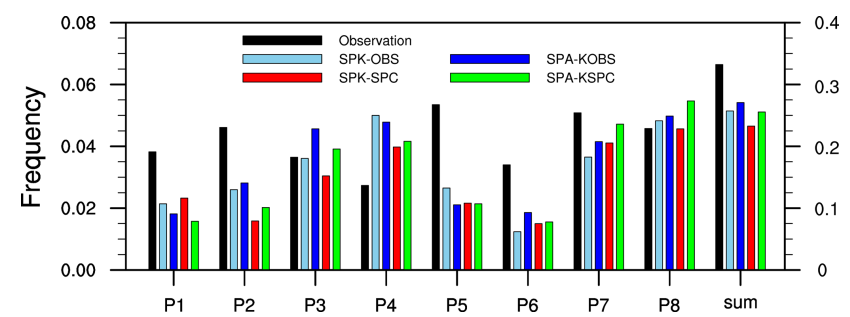

Figure 11. The frequency of strong BSISO activity (amplitude $\geq 1.5$ ) in each phase (P1-P8; the left $y$ axis) and their sum (the right $y$ axis) for NOAA OLR and ERAI $u_{850}$ (black), SPK-OBS (light blue), SPA-KOBS (dark blue), SPK-SPC (red), and SPAKSPC (green).

\section{Discussion}

Despite the correct SST-rainfall phase relationship in SPK simulations, a shorter delay between suppressed convection and warm SST occurs compared to the observation. This may be associated with the configuration of the MC-KPP ocean (lack of full ocean dynamics, high coupling frequency, and fine vertical resolution). As a consequence of the shorter delay, it is easy to surmise the negative effect of air-sea coupling on the amplitude of convection, while its effect on the propagation is not obvious. Overall, intraseasonal SST anomalies in SPK largely damp intraseasonal subtropical convection variability and make a smaller contribution $(8 \%-$ $12 \%)$ to $\partial\langle m\rangle / \partial t$ than those in the ERAI $(12 \%-20 \%)$. Comparing Figs. 4 and 5, we can see propagation is slightly enhanced in SPK relative to SPA over the Indian Ocean; however, coupling makes nearly no difference to the propagating signal over the western Pacific. This may be related to the larger underestimate of the contribution of intraseasonal SST to $\partial\langle m\rangle / \partial t$ over the western Pacific than over the Bay of Bengal (Fig. 8). More importantly, it implies that atmospheric internal processes are essential to the propagation of convection, since SPA simulates BSISO propagation well even without coupling or sub-seasonal SST variability.

Stan et al. (2010) and Neena et al. (2017) reported that SPC showed better ISO simulation skill than SPA with prescribed observed SST. In our experiments, the BSISO variability is similar in SPK-OBS and SPA-KOBS and in SPKSPC and SPA-KSPC, which suggests a limited role for airsea coupling in the simulated BSISO. Comparing SPK-OBS and SPK-SPC strongly suggests that the ocean mean-state biases in SPC improve BSISO amplitude and spatial distribution. This implies that mean-state biases in SPC, not subseasonal air-sea coupled feedbacks, may be the primary reason for the improved BSISO in SPC relative to SPA. While the SPC mean state improves the amplitude and spatial pattern of simulated BSISO convection, it also weakens northward propagation. Besides the SST mean-state biases, it is also important to control the SST gradient biases. Several studies highlighted the importance of horizonal advection of
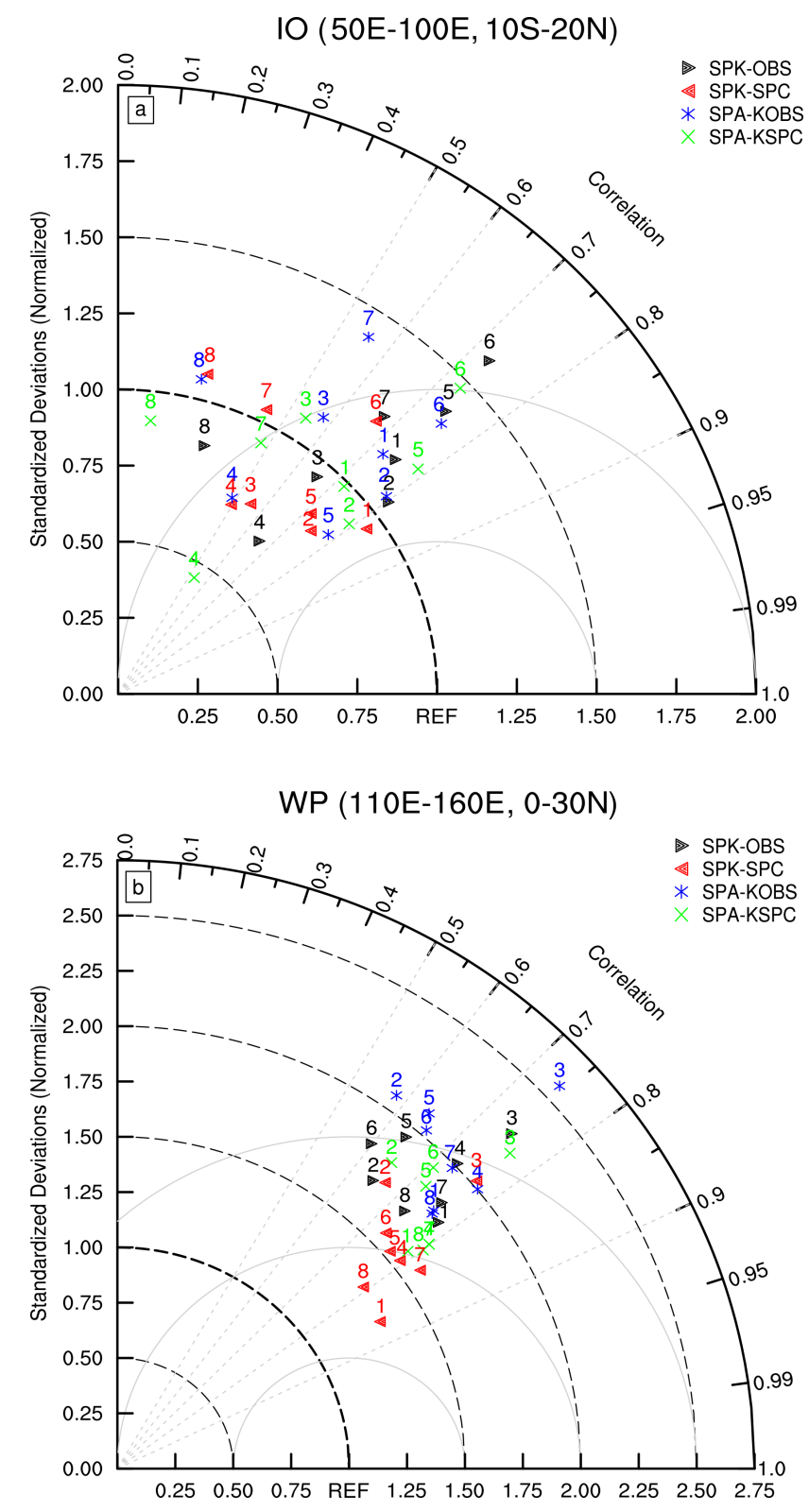

Figure 12. Taylor diagrams for anomalous precipitation in each BSISO phase averaged over (a) the Indian Ocean (IO; $10^{\circ} \mathrm{S}-20^{\circ} \mathrm{N}$, $50-100^{\circ} \mathrm{E}$ ) and (b) western Pacific (WP; 0-30 $\mathrm{N}, 110-160^{\circ} \mathrm{E}$ ). The number above each symbol refers to the BSISO phase.

mean moisture (or $\langle m\rangle$ ) by anomalous wind in the propagation of the ISO (Hsu and Li, 2012; Jiang, 2017; Jiang et al., 2018; DeMott et al., 2019; Gao et al., 2019). Our additional diagnosis revealed that the pattern of $\langle m\rangle$ biases closely follows that of SST biases (not shown). By examining Fig. 1g and $\mathrm{h}$, we would argue that the stronger BSISO variability in SPK-OBS than in SPK-SPC may be related to the enhanced meridional gradients of SST and moisture. A weaker propagating BSISO signal in SPC seems to be associated with the 
reduced horizontal $\langle m\rangle$ advection of mean $\langle m\rangle$ induced by anomalous wind.

In CGCMs with dynamic oceans, it is also important to consider the effect of interannual SST variability (such as the ENSO), due to its strong control on sub-seasonal variability, particularly on the boreal winter MJO (Weaver et al., 2011; Kapur and Zhang, 2012; Klingaman and DeMott, 2020). We note that none of the simulations considered here represent the ENSO or other coupled modes of interannual variability, as the MC-KPP ocean model lacks the requisite ocean dynamics. Using the same simulations, Klingaman and DeMott (2020) found that the intensity and propagation of the boreal winter MJO was strongly suppressed in SPK under the SPC ocean mean state, while here the SPC ocean mean state enhances BSISO amplitude and only slightly weakens its propagation. Klingaman and DeMott (2020) found that the inclusion of the SPC ENSO variability on top of the SPC mean state substantially strengthened the MJO, suggesting that the strong MJO in SPC arose from an excessively intense response to the ENSO. The effect of ENSO is not considered here, which could be a subject for further study.

\section{Summary}

We investigate the roles of ocean mean-state biases and airsea coupling in simulating the BSISO by coupling the SPA to the MC-KPP mixed-layer ocean. To diagnose the sensitivity to the ocean mean state, SPK is constrained to either observed ocean mean state or the ocean mean state from the coupled configuration of SPA with a dynamic ocean (SPC). The SPC mean state introduces substantial cold SST biases across the Indo-Pacific. To diagnose the sensitivity to air-sea coupling under different mean states, SPA is driven by the $31 \mathrm{~d}$ running mean SST from each SPK simulation.

Systematic errors in SPA result in overestimated subtropical summer mean rainfall and intraseasonal variability. These overestimated variables are greatly improved with coupling, or with the SPC ocean mean state. Lag regression composites show that the simulated convection exhibits realistic northward propagation over both the Indian Ocean and western Pacific. However, the strongest convective centre shifts north relative to the observation. Using the SPC ocean mean state degrades the propagating BSISO signal in both coupled and uncoupled simulations, relative to the simulations that use the observed ocean mean state. Air-sea coupling slightly enhances the strength of the propagating signal under both ocean mean states. The coupled simulations capture the SSTrainfall phase relationship reasonably well, but with warm SSTs shifting toward the suppressed convection over the Bay of Bengal relative to the observation. Intraseasonal SST variability plays a similar role in the BSISO MSE budget in the coupled simulations, regardless of the ocean mean state: it damps subtropical convection and favours BSISO northward propagation, but with a smaller contribution ( $8 \%-12 \%)$ than the reanalysis $(12 \%-20 \%)$.

We also examine the simulation skill of propagating BSISO characteristics by using BSISO indices. Experiments with the observed ocean mean state produce a realistic annual cycle of BSISO variance, while the simulations with the SPC mean state result in a 1-month delay in the onset of BSISO activity. Air-sea coupling weakens convective variability mainly through suppressing the first EOF mode. Different from the observation, all model simulations favour strong BSISO activity in off-equatorial regions, which is associated with intense subtropical variability. Overall, the simulations using the SPC ocean mean state produce a more improved BSISO than those using the observed ocean mean state, in terms of both amplitude and pattern correlation of anomalous precipitation. Air-sea coupling improves the BSISO fidelity in most phases. The enhancement of simulated BSISO by the ocean mean state and air-sea coupling largely arises from suppressing erroneously strong subtropical convection.

In our study, air-sea coupling has a similar effect on the simulated BSISO under different ocean background states, suggesting that the role of coupling may largely depend on the phase relationship between the convection and SST anomalies. Compared to daily coupling frequency between the atmosphere and ocean components of CGCMs, improved fidelity for the BSISO simulation is shown in CGCMs with sub-daily coupling frequency (Woolnough et al., 2007; Klingaman et al., 2011; Hu et al., 2015). In our study, the model ocean tends to respond quickly to the atmospheric convection, which may be associated with the sensitive mixed layer depth due to the absent ocean dynamics in KPP. Therefore, to better understand the role of coupling in the simulated ISO, efforts should be aimed at simulating a realistic phase relationship between the ISO convection and SST anomalies.

Code and data availability. The SPK source code is publicly available through Zenodo (Klingaman, 2020, https://doi.org/10.5281/zenodo.4021071). Data used to reproduce the figures are publicly available through figshare (Gao, 2020, https://doi.org/10.6084/m9.figshare.c.4874406.v3). ERAI reanalysis data can be obtained from the https://apps.ecmwf.int/datasets (last access: 30 October 2020) (ECMWF, 2020). NOAA OLR data can be obtained from the https://psl.noaa.gov/psd/data/ gridded/data.interp_OLR.html (last access: 30 October 2020) (Physical Sciences Laboratory, 2020). GPCP precipitation can be obtained from the https://www.ncei.noaa.gov/data/ global-precipitation-climatology-project-gpcp-daily/access (last access: 30 October 2020) (NOAA, 2020).

Author contributions. YG and PCH conducted analyses and wrote the paper. NPK and CAD designed and performed SPK simulations 
presented in the paper. All authors gave comments and contributed to the development of the paper.

Competing interests. The authors declare that they have no conflict of interest.

Acknowledgements. Yingxia Gao and Pang-Chi Hsu are supported by the National Key R\&D Program of China (2018YFC1505804) and NUIST-UoR Open Project (1321011901004). Nicholas P. Klingaman is supported by an Independent Research Fellowship from the UK Natural Environment Research Council (NE/L010976/1) and a grant from the NOAA Modeling, Analysis, Predictions and Projections program (NA16OAR4310071). Charlotte A. DeMott is supported by the National Science Foundation (NSF 1445191) and the NOAA Modeling, Analysis, Predictions and Projections program (NA16OAR4310094). The valuable comments and suggestions from anonymous reviewers significantly improved the paper and are much appreciated.

Financial support. This research has been supported by the National Key R \& D Program of China (grant no. 2018YFC1505804), the NUIST-UoR Open Project (grant no. 1321011901004), the Independent Research Fellowship from the UK Natural Environment Research Council (grant no. NE/L010976/1), the NOAA Modeling, Analysis, Predictions and Projections program (grant no. NA16OAR4310071), the National Science Foundation (grant no. NSF 1445191), and the NOAA Modeling, Analysis, Predictions and Projections program (grant no. NA16OAR4310094).

Review statement. This paper was edited by Richard Neale and reviewed by two anonymous referees.

\section{References}

Annamalai, H. and Slingo, J. M.: Active/break cycles: Diagnosis of the intraseasonal variability of the Asian summer monsoon, Clim. Dynam., 18, 85-102, https://doi.org/10.1007/s003820100161, 2001.

Annamalai, H. and Sperber, K. R.: Regional heat sources and the active and break phases of boreal summer intraseasonal (30-50 day) variability, J. Atmos. Sci., 62, 2726-2748, https://doi.org/10.1175/JAS3504.1, 2005.

Benedict, J. J. and Randall, D. A.: Structure of the Madden-Julian oscillation in the superparameterized CAM, J. Atmos. Sci., 66, 3277-3296, https://doi.org/10.1175/2009JAS3030.1, 2009.

Bernie, D. J., Woolnough, S. J., Slingo, J. M., and Guilyardi, E.: Modeling diurnal and intraseasonal variability of the ocean mixed layer, J. Climate, 18, 1190-1202, https://doi.org/10.1175/JCLI3319.1, 2005.

Bollasina, M. A. and Ming, Y.: The general circulation model precipitation bias over the southwestern equatorial Indian Ocean and its implications for simulating the South Asian monsoon,
Clim. Dynam., 40, 823-838, https://doi.org/10.1007/s00382012-1347-7, 2013.

Danabasoglu, G., Large, W. G., Tribbia, J. J., Gent, P. R., Briegleb, B. P., and McWilliams, J. C.: Diurnal coupling in the tropical oceans of CCSM3, J. Climate, 19, 2347-2365, 2006.

Dee, D. P., Uppala, S. M., Simmons, A. J., Berrisford, P., Poli, P., Kobayashi, S., Andrae, U., Balmaseda, M. A., Balsamo, G., Bauer, P., Bechtold, P., Beljaars, A. C. M., van de Berg, L., Bidlot, J., Bormann, N., Delsol, C., Dragani, R., Fuentes, M., Geer, A. J., Haimberger, L., Healy, S. B., Hersbach, H., Hólm, E. V., Isaksen, L., Kållberg, P., Köhler, M., Matricardi, M., McNally, A. P., Monge-Sanz, B. M., Morcrette, J.-J., Park, B.-K., Peubey, C., de Rosnay, P., Tavolato, C., Thépaut, J.-N., and Vitart, F.: The ERA-Interim reanalysis: Configuration and performance of the data assimilation system, Q. J. Roy. Meteorol. Soc., 137, 553597, https://doi.org/10.1002/qj.828, 2011.

DeMott, C. A., Stan, C., Randall, D. A., Kinter, J. L., and Khairoutdinov, M.: The Asian monsoon in the superparameterized CCSM and Its relationship to tropical wave activity, J. Climate, 24, 5134-5156, https://doi.org/10.1175/2011JCLI4202.1, 2011.

DeMott, C. A., Stan, C., Randall, D. A., and Branson, M. D.: Intraseasonal variability in coupled GCMs: The roles of ocean feedbacks and model physics, J. Climate, 27, 4970-4995, https://doi.org/10.1175/JCLI-D-13-00760.1, 2014.

DeMott, C. A., Klingaman, N. P., and Woolnough, S. J.: Atmosphere-ocean coupled processes in the MaddenJulian oscillation, Rev. Geophys., 53, 1099-1154, https://doi.org/10.1002/2014RG000478, 2015.

DeMott, C. A., Benedict, J. J., Klingaman, N. P., Woolnough, S. J., and Randall, D. A.: Diagnosing ocean feedbacks to the MJO: SST-modulated surface fluxes and the moist static energy budget, J. Geophys. Res.-Atmos., 121, 8350-8373, https://doi.org/10.1002/2016JD025098, 2016.

DeMott, C. A., Klingaman, N. P., Tseng, W.-L., Burt, M. A., Gao, Y., and Randall, D. A.: The convection connection: How ocean feedbacks affect tropical mean moisture and MJO propagation, J. Geophys. Res.-Atmos., 124, 11910-11931, https://doi.org/10.1029/2019JD031015, 2019.

Ding, Q. and Wang, B.: Intraseasonal teleconnection between the summer Eurasian wave train and the Indian monsoon, J. Climate, 20, 3751-3767, https://doi.org/10.1175/JCLI4221.1, 2007.

ECMWF: Public Datasets, available at: https://apps.ecmwf.int/ datasets/, last access: 30 October 2020.

$\mathrm{Fu}, \mathrm{X}$. and Wang, B.: Differences of boreal summer intraseasonal oscillations simulated in an atmosphere-ocean coupled model and an atmosphere-only model, J. Climate, 17, 1263-1271, 2004.

Gao, Y.: BSISO in SP GCMs: effects of airsea coupling and mean-state biases, figshare, https://doi.org/10.6084/m9.figshare.c.4874406.v3, 2020.

Gao, Y., Klingaman, N. P., DeMott, C. A., and Hsu, P.: Diagnosing ocean feedbacks to the BSISO: SST-modulated surface fluxes and the moist static energy budget, J. Geophys. Res.-Atmos., 124, 146-170, https://doi.org/10.1029/2018JD029303, 2019.

Hendon, H. H.: Impact of air-sea coupling on the MaddenJulian oscillation in a general circulation model, J. Atmos. Sci., 57, 3939-3952, https://doi.org/10.1175/15200469(2001)058<3939:IOASCO>2.0.CO;2, 2000.

Hirons, L. C., Klingaman, N. P., and Woolnough, S. J.: MetUM-GOML1: a near-globally coupled atmosphere- 
ocean-mixed-layer model, Geosci. Model Dev., 8, 363-379, https://doi.org/10.5194/gmd-8-363-2015, 2015.

Hsu, P.-C. and Li, T.: Role of the boundary layer moisture asymmetry in causing the eastward propagation of the Madden-Julian Oscillation, J. Climate, 25, 4914-4931, https://doi.org/10.1175/JCLI-D-11-00310.1, 2012.

Hsu, P.-C., Lee, J.-Y., and Ha, K.-J.: Influence of boreal summer intraseasonal oscillation on rainfall extremes in southern China, Int. J. Climatol., 36, 1403-1412, https://doi.org/10.1002/joc.4433, 2016.

Hsu, P.-C., Lee, J.-Y., Ha, K.-J., and Tsou, C.-H.: Influences of boreal summer intraseasonal oscillation on heat waves in monsoon Asia, J. Climate, 30, 7191-7211, https://doi.org/10.1175/JCLID-16-0505.1, 2017.

Hsu, P.-C., Qian, Y., Liu, Y., Murakami, H., and Gao, Y.: Role of abnormally enhanced MJO over the Western Pacific in the formation and subseasonal predictability of the record-breaking Northeast Asian heatwave in the summer of 2018, J. Climate, 33, 3333-3349, https://doi.org/10.1175/JCLI-D-19-0337.1, 2020.

$\mathrm{Hu}$, W., Duan, A., and Wu, G.: Impact of subdaily air-sea interaction on simulating intraseasonal oscillations over the tropical Asian monsoon region, J. Climate, 28, 1057-1073, https://doi.org/10.1175/JCLI-D-14-00407.1, 2015.

$\mathrm{Hu}, \mathrm{W} .$, Duan, A., and He, B.: Evaluation of intra-seasonal oscillation simulations in IPCC AR5 coupled GCMs associated with the Asian summer monsoon, Int. J. Climatol., 37, 476-496, https://doi.org/10.1002/joc.5016, 2017.

Huffman, G. J., Adler, R. F., Morrissey, M. M., Bolvin, D. T., Curtis, S., Joyce, R., McGavock, B., and Susskind, J.: Global Precipitation at One-Degree Daily Resolution from Multisatellite Observations, J. Hydrometeorol., 2, 36-50, https://doi.org/10.1175/15257541(2001)002<0036:GPAODD>2.0.CO;2, 2001.

Inness, P. M., Slingo, J. M., Guilyardi, E., and Cole, J.: Simulation of the Madden-Julian oscillation in a coupled general circulation model. Part II: The role of the basic state, J. Climate, 16, 365-382, https://doi.org/10.1175/15200442(2003)016<0365:SOTMJO>2.0.CO;2, 2003.

Jiang, X.: Key processes for the eastward propagation of the Madden-Julian Oscillation based on multimodel simulations. J. Geophys. Res.-Atmos., 122, 755-770, https://doi.org/10.1002/2016JD025955, 2017.

Jiang, X., Waliser, D. E., Xavier, P. K., Petch, J., Klingaman, N. P., Woolnough, S. J., Guan, B., Bellon, G., Crueger, T., DeMott, C., Hannay, C., Lin, H., Hu, W., Kim, D., Lappen, C.L., Lu, M.-M., Ma, H.-Y., Miyakawa, T., Ridout, J. A., Schubert, S. D., Scinocca, J., Seo, K.-H., Shindo, E., Song, X., Stan, C., Tseng, W.-L., Wang, W., Wu, T., Wu, X., Wyser, K., Zhang, G. J., and Zhu, H.: Vertical structure and physical processes of the Madden-Julian oscillation: Exploring key model physics in climate simulations, J. Geophys. Res.-Atmos., 120, 4718-4748, https://doi.org/10.1002/2014JD022375, 2015.

Jiang, X., Zhao, M., Maloney, E. D., and Waliser, D. E.: Convective moisture adjustment time scale as a key factor in regulating model amplitude of the MaddenJulian oscillation, Geophys. Res. Lett., 43, 10412-10419, https://doi.org/10.1002/2016GL070898, 2016.

Jiang, X., Adames, A. F., Zhao, M., Waliser, D., and Maloney, E.: A unified moisture moist framework for seasonality of MJO propa- gation, J. Climate, 31, 4215-4224, https://doi.org/10.1175/JCLID-17-0671.1, 2018.

Kapur, A. and Zhang, C.: Multiplicative MJO forcing of ENSO, J. Climate, 25, 8132-8147, https://doi.org/10.1175/JCLI-D-1100609.1, 2012.

Kessler, W. S., McPhaden, M. J., and Weickmann, K. M.: Forcing of intraseasonal Kelvin waves in the equatorial Pacific, J. Geophys. Res., 100, 10613-10631, https://doi.org/10.1029/95JC00382, 1995.

Khairoutdinov, M., Randall, D., and DeMott, C.: Simulations of the atmospheric general circulation using a cloud-resolving model as a superparameterization of physical processes, J. Atmos. Sci., 62, 2136-2154, https://doi.org/10.1175/JAS3453.1, 2005.

Khairoutdinov, M. F. and Randall, D. A.: Cloud resolving modeling of the ARM summer 1997 IOP: Model formulation, results, uncertainties, and sensitivities, J. Atmos. Sci., 60, 607-625, https://doi.org/10.1175/15200469(2003)060<0607:CRMOTA>2.0.CO;2, 2003.

Klingaman, N. P.: spcam3-kpp: SPCAM3-KPP release 1.0, Zenodo, https://doi.org/10.5281/zenodo.4021071, 2020.

Klingaman, N. P. and DeMott, C. A.: Mean state biases and interannual variability affect perceived sensitivities of the MaddenJulian oscillation to air-sea coupling, J. Adv. Model. Earth Syst., 12, e2019MS001799, https://doi.org/10.1029/2019MS001799, 2020.

Klingaman, N. P. and Woolnough, S. J.: The role of air-sea coupling in the simulation of the Madden-Julian oscillation in the Hadley Centre model, Q. J. Roy. Meteorol. Soc., 140, 2272 2286, https://doi.org/10.1002/qj.2295, 2014.

Klingaman, N. P., Woolnough, S. J., Weller, H., and Slingo, J. M.: The impact of finer-resolution air-sea coupling on the intraseasonal oscillation of the Indian monsoon, J. Climate, 24, 24512468, https://doi.org/10.1175/2010JCLI3868.1, 2011.

Large, W., McWilliams, J., and Doney, S.: Oceanic vertical mixing: A review and a model with a nonlocal boundary layer parameterization, Rev. Geophys., 32, 363-403, 1994.

Lau, W. K. M. and Waliser, D. E.: Intraseasonal variability in the atmosphere-ocean climate system, 2nd Edn., Springer, Berlin, 2012.

Lee, J.-Y., Wang, B., Wheeler, M. C., Fu, X., Waliser, D. E., and Kang, I.-S.: Real-time multivariate indices for the boreal summer intraseasonal oscillation over the Asian summer monsoon region, Clim. Dynam., 40, 493-509, https://doi.org/10.1007/s00382012-1544-4, 2013.

Levine, R. C. and Turner, A. G.: Dependence of Indian monsoon rainfall on moisture fluxes across the Arabian Sea and the impact of coupled model sea surface temperature biases, Clim. Dynam., 38, 2167-2190, https://doi.org/10.1007/s00382-011-1096z, 2012

Li, J., Mao, J., and Wu, G.: A case study of the impact of boreal summer intraseasonal oscillations on Yangtze rainfall, Clim. Dynam., 44, 2683-2702, https://doi.org/10.1007/s00382-014-24259, 2015

Liebmann, B. and Smith, C. A.: Description of a complete (interpolated) outgoing long wave radiation dataset, B. Am. Meteorol. Soc., 77, 1275-1277, 1996.

Lin, J.-L., Kiladis, G. N., Mapes, B. E., Weickmann, K. M., Sperber, K. R., Lin, W., Wheeler, M. C., Schubert, S. D., Del Genio, A., Donner, L. J., Emori, S., Gueremy, J.-F., Hourdin, F., Rasch, P. J., 
Roeckner, E., and Scinocca, J. F.: Tropical intraseasonal variability in 14 IPCC AR4 climate models. Part I: Convective signals, J. Climate, 19, 2665-2690, https://doi.org/10.1175/JCLI3735.1, 2006.

Liu, Y. and Hus, P.-C.: Long-term changes in wintertime persistent heavy rainfall over southern China contributed by the Madden-Julian Oscillation, Atmos. Ocean. Sci. Lett., 12, 361368, https://doi.org/10.1080/16742834.2019.1639471, 2019.

Madden, R. A. and Julian, P. R.: Detection of a 40-50 Day Oscillation in the Zonal Wind in the Tropical Pacific, J. Atmos. Sci., 28, 702-708, https://doi.org/10.1175/15200469(1971)028<0702:DOADOI >2.0.CO;2, 1971.

Madden, R. A. and Julian, P. R.: Description of global-scale circulation cells in the tropics with a 40-50 day period, J. Atmos. Sci., 29, 1109-1123, https://doi.org/10.1175/15200469(1972)029<1109:DOGSCC>2.0.CO;2, 1972.

Maloney, E. D.: The moist static energy budget of a composite tropical intraseasonal oscillation in a climate model, J. Climate, 22, 711-729, https://doi.org/10.1175/2008JCLI2542.1, 2009.

Maloney, E. D. and Hartmann, D. L.: The sensitivity of intraseasonal variability in the NCAR CCM3 to changes in convective parameterization, J. Climate, 14, 2015-2034, https://doi.org/10.1175/15200442(2001)014<2015:TSOIVI>2.0.CO;2, 2001.

McPhaden, M. J.: Evolution of the 2002/2003 El Nino, B. Am. Meteorol. Soc., 85, 677-695, 2004.

Moon, J.-Y., Wang, B., Ha, K.-J., and Lee, J.-Y.: Teleconnections associated with Northern Hemisphere summer monsoon intraseasonal oscillation, Clim. Dynam., 40, 2761-2774, https://doi.org/10.1007/s00382-012-1394-0, 2013.

Misra, V., Marx, L., Brunke, M., and Zeng, X.: The equatorial Pacific cold tongue bias in a coupled climate model, J. Climate, 21, 5852-5869, https://doi.org/10.1175/2008JCLI2205.1, 2008.

Neena, J. M., Waliser, D., and Jiang, X.: Model performance metrics and process diagnostics for boreal summer intraseasonal variability, Clim. Dynam., 48, 1661-1683, https://doi.org/10.1007/s00382-016-3166-8, 2017.

NOAA: Index of /data/global-precipitation-climatology-projectgpcp-daily/access, available at: https://www.ncei.noaa.gov/data/ global-precipitation-climatology-project-gpcp-daily/access/, last access: 30 October 2020.

Physical Sciences Laboratory: NOAA Interpolated Outgoing Longwave Radiation (OLR), available at: https://psl.noaa.gov/data/ gridded/data.interp_OLR.html, last access: 30 October 2020.

Randall, D. A., Wood, R. A., Bony, S., Colman, R., Fichefet, T., Fyfe, J., Kattsov, V., Pitman, A., Shukla, J., Srinivasan, J., Stouffer, R. J., Sumi, A., and Taylor, K. E.: Climate models and their evaluation, in: Climate Change 2007: The Physical Science Basis. Contribution of Working Group I to the Fourth Assessment Report of the Intergovernmental Panel on Climate Change, edited by: Solomon, S., Qin, D., Manning, M., Chen, Z., Marquis, M., Averyt, K. B., Tignor, M., and Miller, H. L., Cambridge University Press, Cambridge, UK and New York, USA, 589-662, 2007.

Ren, X., Yang, X.-Q., and Sun, X.: Zonal oscillation of western Pacific subtropical high and subseasonal SST variations during Yangtze persistent heavy rainfall events, J. Climate, 26, 89298946, https://doi.org/10.1175/JCLI-D-12-00861.1, 2013.

Sabeerali, C. T., Ramu Dandi, A., Dhakate, A., Salunke, K., Mahapatra, S., and Rao, S. A.: Simulation of bo- real summer intraseasonal oscillations in the latest CMIP5 coupled GCMs, J. Geophys. Res.-Atmos., 118, 4401-4420, https://doi.org/10.1002/jgrd.50403, 2013.

Seo, K.-H., Schemm, J.-K. E., Wang, W., and Kumar, A.: The boreal summer intraseasonal oscillation simulated in the NCEP climate forecast system: The effect of sea surface temperature, Mon. Weather Rev., 135, 1807-1827, https://doi.org/10.1175/MWR3369.1, 2007.

Smith, D. M. and Murphy, J. M.: An objective ocean temperature and salinity analysis using covariances from a global climate model, J. Geophys. Res., 112, C02022, https://doi.org/10.1029/2005JC003172, 2007.

Sperber, K. R. and Annamalai, H.: Coupled model simulations of boreal summer intraseasonal (30-50 day) variability, Part 1: Systematic errors and caution on use of metrics, Clim. Dynam., 31, 345-372, https://doi.org/10.1007/s00382-008-0367-9, 2008.

Sperber, K. R., Slingo, J. M., and Annamalai, H.: Predictability and the relationship between subseasonal and interannual variability during the Asian summer monsoon, Q. J. Roy. Meteorol. Soc., 126, 2545-2574, https://doi.org/10.1002/qj.49712656810, 2000.

Sperber, K. R., Gualdi, S., Legutke, S., and Gayler, V.: The Madden-Julian oscillation in ECHAM4 coupled and uncoupled general circulation models, Clim. Dynam., 25, 117-140, https://doi.org/10.1007/s00382-005-0026-3, 2005.

Sperber, K. R., Annamalai, H., Kang, I.-S., Kitoh, A., Moise, A., Turner, A., Wang, B., and Zhou, T.: The Asian summer monsoon: an intercomparison of CMIP5 vs. CMIP3 simulations of the late 20th century, Clim. Dynam., 41, 2711-2744, https://doi.org/10.1007/s00382-012-1607-6, 2013.

Stan, C.: The role of SST variability in the simulation of the MJO, Clim. Dynam., 51, 2943-2964, https://doi.org/10.1007/s00382017-4058-2, 2018.

Stan, C., Khairoutdinov, M., DeMott, C. A., Krishnamurthy, V., Straus, D. M., Randall, D. A., Kinter, J. L., and Shukla, J.: An ocean-atmosphere climate simulation with an embedded cloud resolving model, Geophys. Res. Lett., 37, L01702, https://doi.org/10.1029/2009GL040822, 2010.

Waliser, D. E., Lau, K. M., and Kim, J.-H.: The influence of coupled sea surface temperatures on the Madden-Julian Oscillation: A model perturbation experiment, J. Atmos. Sci., 56, 333-358, 1999.

Waliser, D. E., Jin, K., Kang, I.-S., Stern, W. F., Schubert, S. D., Wu, M. L. C., Lau, K.-M., Lee, M.-I., Krishnamurthy, V., Kitoh, A., Meehl, G. A., Galin, V. Y., Satyan, V., Mandke, S. K., Wu, G., Liu, Y., and Park, C.-K.: AGCM simulations of intraseasonal variability associated with the Asian summer monsoon, Clim. Dynam., 21, 423-446, https://doi.org/10.1007/s00382003-0337-1, 2003.

Wang, B., Webster, P. J., and Teng, H.: Antecedents and self-induction of active-break south Asian monsoon unraveled by satellites, Geophys. Res. Lett., 32, L04704, https://doi.org/10.1029/2004GL020996, 2005.

Wang, B., Webster, P., Kikuchi, K., Yasunari, T., and Qi, Y.: Boreal summer quasi-monthly oscillation in the global tropics, Clim. Dynam., 27, 661-675, https://doi.org/10.1007/s00382006-0163-3, 2006.

Weare, B. C., Strub, P. T., and Samuel, M. D.: Annual mean surface heat fluxes in the tropical Pacific ocean, J. 
Phys. Oceanogr., 11, 705-717, https://doi.org/10.1175/15200485(1981)011<0705:AMSHFI>2.0.CO;2, 1981.

Weaver, S. J., Wang, W., Chen, M., and Kumar, A.: Representation of MJO variability in the NCEP climate forecast system, J. Climate, 24, 4676-4694, https://doi.org/10.1175/2011JCLI4188.1, 2011.

Wheeler, M. and Kiladis, G. N.: Convectively coupled equatorial waves: Analysis of clouds and temperature in the wavenumber-frequency domain, J. Atmos. Sci., 56, 374-399, https://doi.org/10.1175/15200469(1999)056<0374:CCEWAO>2.0.CO;2, 1999.

Woolnough, S. J., Vitart, F., and Balmaseda, M. A.: The role of the ocean in the Madden-Julian oscillation: Implications for MJO prediction, Q. J. Roy. Meteorol. Soc., 133), 117-128, https://doi.org/10.1002/qj.4, 2007.
Wu, X., Deng, L., Song, X., Vettoretti, G., Peltier, W. R., and Zhang, G. J.: Impact of a modified convective scheme on the Madden-Julian Oscillation and El Niño-Southern Oscillation in a coupled climate model, Geophys. Res. Lett., 34, L16823, https://doi.org/10.1029/2007GL030637, 2007.

Yasunari, T.: Cloudiness fluctuations associated with the northern summer monsoon, J. Meteorol. Soc. Jpn., 57, 227-242, 1979.

Zhang, C.: Madden-Julian oscillation, Rev. Geophys., 43, RG2003, https://doi.org/10.1029/2004RG000158, 2005.

Zhang, C. and Gottschalck, J.: SST anomalies of ENSO and the Madden-Julian oscillation in the equatorial $\mathrm{Pa}$ cific, J. Climate, 15, 2429-2445, https://doi.org/10.1175/15200442(2002)015<2429:SAOEAT>2.0.CO;2, 2002. 